\title{
The potential influence of Asian and African mineral dust on ice, mixed-phase and liquid water clouds
}

\author{
A. Wiacek ${ }^{1}$, T. Peter ${ }^{2}$, and U. Lohmann ${ }^{2}$ \\ ${ }^{1}$ Department of Physics and Atmospheric Science, Dalhousie University, Halifax, Nova Scotia, Canada \\ ${ }^{2}$ Institute for Atmospheric and Climate Science, ETH Zürich, Switzerland
}

Received: 8 December 2009 - Published in Atmos. Chem. Phys. Discuss.: 8 December 2009

Revised: 30 June 2010 - Accepted: 27 August 2010 - Published: 16 September 2010

\begin{abstract}
This modelling study explores the availability of mineral dust particles as ice nuclei for interactions with ice, mixed-phase and liquid water clouds, also tracking the particles' history of cloud-processing. We performed 61320 oneweek forward trajectory calculations originating near the surface of major dust emitting regions in Africa and Asia using high-resolution meteorological analysis fields for the year 2007. Dust-bearing trajectories were assumed to be those coinciding with known dust emission seasons, without explicitly modelling dust emission and deposition processes. We found that dust emissions from Asian deserts lead to a higher potential for interactions with high ice clouds, despite being the climatologically much smaller dust emission source. This is due to Asian regions experiencing significantly more ascent than African regions, with strongest ascent in the Asian Taklimakan desert at $\sim 25 \%, \sim 40 \%$ and $10 \%$ of trajectories ascending to $300 \mathrm{hPa}$ in spring, summer and fall, respectively. The specific humidity at each trajectory's starting point was transported in a Lagrangian manner and relative humidities with respect to water and ice were calculated in 6-h steps downstream, allowing us to estimate the formation of liquid, mixed-phase and ice clouds. Downstream of the investigated dust sources, practically none of the simulated air parcels reached conditions of homogeneous ice nucleation $\left(T \lesssim-40^{\circ} \mathrm{C}\right)$ along trajectories that have not experienced water saturation first. By far the largest fraction of cloud forming trajectories entered conditions of mixed-phase clouds, where mineral dust will potentially exert the biggest influence. The majority of trajectories also passed through atmospheric regions supersaturated with respect to ice but
\end{abstract}

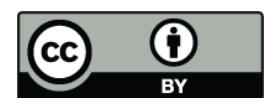

Correspondence to: A. Wiacek (aldona.wiacek@dal.ca) subsaturated with respect to water, where so-called "warm ice clouds" $\left(T \gtrsim-40^{\circ} \mathrm{C}\right)$ theoretically may form prior to supercooled water or mixed-phase clouds. The importance of "warm ice clouds" and the general influence of dust in the mixed-phase cloud region are highly uncertain due to both a considerable scatter in recent laboratory data from ice nucleation experiments, which we briefly review in this work, and due to uncertainties in sub-grid scale vertical transport processes unresolved by the present trajectory analysis. For "classical" cirrus-forming temperatures $\left(T \lesssim-40^{\circ} \mathrm{C}\right)$, our results show that only mineral dust ice nuclei that underwent mixed-phase cloud-processing, most likely acquiring coatings of organic or inorganic material, are likely to be relevant. While the potential paucity of deposition ice nuclei shown in this work dimishes the possibility of deposition nucleation, the absence of liquid water droplets at $T \lesssim-40^{\circ} \mathrm{C}$ makes the less explored contact freezing mechanism (involving droplet collisions with bare ice nuclei) highly inefficient. These factors together indicate the necessity of further systematic studies of immersion mode ice nucleation on mineral dust suspended in atmospherically relevant coatings.

\section{Introduction}

Atmospheric aerosols are well known to exert both direct and indirect radiative effects on the climate system, with the latter arising through aerosol interactions with clouds and the resultant changes in cloud reflectivity, cloud lifetime, and precipitation rates (Forster et al., 2007). Naturally occurring mineral dust is, on a mass basis, the most abundant aerosol in the atmosphere (Satheesh and Moorthy, 2005). It is known to fertilize the oceans with nutrients, as well as to cause a strong

Published by Copernicus Publications on behalf of the European Geosciences Union. 
direct radiative effect, which feeds back on surface temperatures and winds, as well as on climate (Tegen, 2003). Like other aerosols, mineral dust is also capable of exerting an indirect effect on the climate system. This is thought to occur primarily via the ice phase of clouds and precipitation, and it represents a big uncertainty in the indirect effect of aerosols (Denman et al., 2007). Challenges in modelling dust emission, transport and deposition processes (Textor et al., 2006; Cakmur et al., 2006) combined with unresolved questions concerning the role of dust in ice nucleation (e.g., Zimmermann et al., 2008 and references therein) lead to corresponding uncertainties in quantitative, global model estimates of the impact of mineral dust on the ice phase of clouds and precipitation (e.g., Hoose et al., 2008; Storelvmo et al., 2008).

It has been known for a long time from both observations and laboratory studies that mineral dust particles are efficient ice nuclei (e.g., Mason and Maybank, 1958; Isono et al., 1959). Recent field measurements both confirm this (e.g. DeMott et al., 2003a, b) and also give in situ evidence of mineral dust in ice crystal residuals (e.g. Cziczo et al., 2004a; Twohy and Poellot, 2005). Additionally, polarization LIDAR measurements provide further evidence for both African (Sassen et al., 2003; Ansmann et al., 2005, 2008, 2009) and Asian (Sassen, 2002, 2005; Sakai et al., 2004) desert dust causing the glaciation of supercooled water clouds at a wide range of temperatures. In general, tropospheric ice may occur at high altitudes and low temperatures $\left(T \lesssim-40^{\circ} \mathrm{C}\right)$ in cirrus clouds or at intermediate altitudes and temperatures $\left(-40^{\circ} \mathrm{C} \lesssim T<0^{\circ} \mathrm{C}\right)$ in mixed-phase clouds, which contain an external mixture of ice crystals and supercooled water droplets. In the cold regime, homogeneous nucleation of ice crystals is possible (Koop et al., 2000), while in the warmer regime, homogeneous ice nucleation is impossible and ice can only form via heterogeneous nucleation processes, i.e., immersion and deposition freezing, possibly also the less explored contact or condensation freezing (see, e.g., Pruppacher and Klett (1997) or Field et al. (2006) for a brief review). Laboratory studies have shown that deposition freezing is a very efficient heterogeneous ice nucleation mechanism in the cold cirrus regime (Möhler et al., 2006). On the other hand, some combination of contact and immersion freezing is thought to control heterogeneous ice formation in the warmer temperature regime (e.g., Hobbs and Rangno, 1985; Mason and Maybank, 1958; Hoffer, 1961), although deposition freezing is also observed at warmer temperatures for larger particles and/or higher surface defects (e.g., Roberts and Hallett, 1968; Zimmermann et al., 2008).

One goal of our modelling study is to assess the availability of "bare" (i.e. without coating by atmospheric constituents) mineral dust particles capable of serving as deposition ice nuclei (IN) in cirrus-forming regions of the atmosphere. For this purpose we accept only particles not having experienced water saturation, or, in other words, particles not having experienced liquid and/or mixed-phase cloud processing, because the ice nucleation efficiency of mineral dust is thought to decrease when it acquires chemical coatings (containing, e.g., nitric or sulphuric acids, or organics) through processing in liquid clouds. Additionally, relaxing the no-water-saturation condition, we explored the potential for interactions of mineral dust with mixed-phase clouds as coated immersion IN, thought to operate at colder temperatures than uncoated contact or deposition IN. Finally we examined the potential for interaction of mineral dust as cloud condensation nuclei $(\mathrm{CCN})$ in warm water clouds $\left(T>0{ }^{\circ} \mathrm{C}\right)$. In Sect. 2, we briefly describe and contrast the dust emission and transport characteristics of the Asian and African dust emitting regions that are the focus of our study. In Sect. 3, we outline our approach to trajectory modelling (including some limitations) and our subsequent data analysis. Section 4 presents the main results of our trajectory analysis, again highlighting differences between Asian and African dust emission regions. Finally, a summary and conclusions are given in Sect. 5.

\section{African and Asian dust emission regions}

\subsection{Seasonality of dust emission}

Mineral dust is emitted every few days in large quantities (routinely observable from space) from sources in the Sahara in the summer and from sources in Asia in the spring, although less spectacular emissions continue throughout the year in many source regions, notably the Taklimakan and Bodélé. The Saharan dust source accounts for nearly two thirds of the total mass of global dust emissions, and, to first order, the Asian dust source makes up the balance (Satheesh and Moorthy, 2005). While the world's "dust belt" is a broad arid region spanning North Africa, the Middle East, Central Asia, and China, dust sources are preferentially associated with either topographical lows (e.g., ancient lake beds) or, in elevated regions, with intermountain basins (Prospero et al., 2002). Figure 1 shows with color-coded circles the locations of Asian and African dust regions used in our study, superimposed on a map of preferential dust sources, adapted from Tegen (2003). Satellite measurements have shown the West African desert and the Bodélé Depression, surrounding present-day Lake Chad, to be the major dust source regions in Africa (Prospero et al., 2002). The former is larger in area, less intense in dust emission and active primarily from May to August, while the latter is smaller in area, more intense in dust emission and exhibits considerable dust activity throughout the year, peaking in winter, and exhibiting a summer minimum (Washington and Todd, 2005; Engelstaedter et al., 2006). The work of Schepanski et al. (2007) points out that West Africa is not necessarily a major dust source region, however, high dust aerosol optical thicknesses often found therein make it nonetheless suitable for our study. 

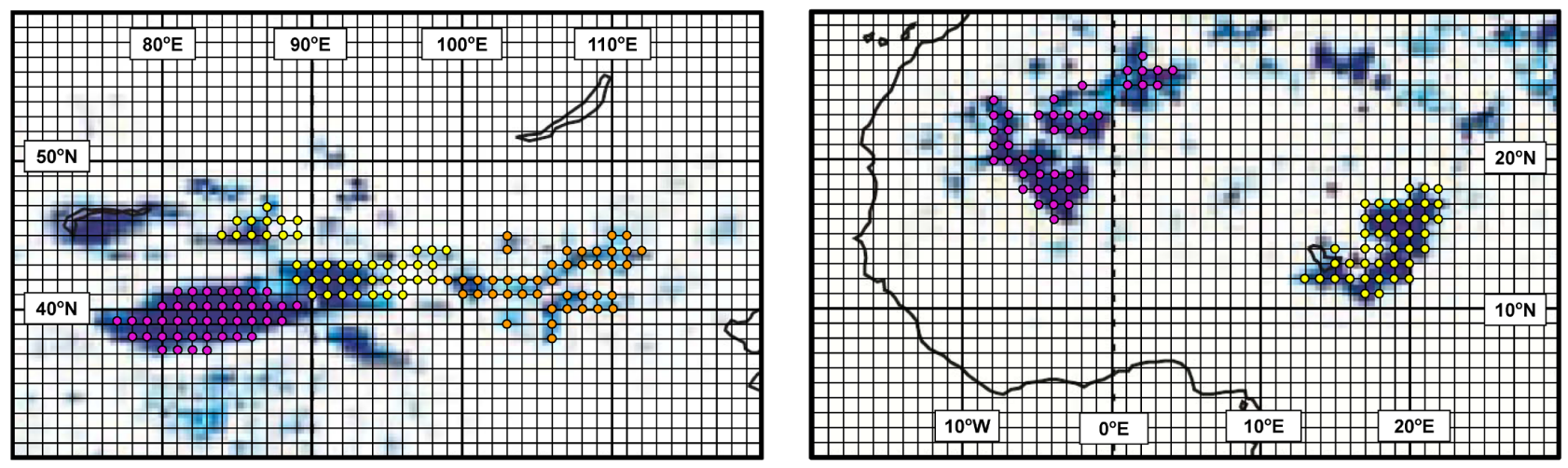

Fig. 1. Circles show the locations of Asian (left) and African (right) trajectory starting points (42 per region) used in this study, superimposed on a map (adapted from Tegen, 2003) of preferential dust source areas (in blue) derived from potential past lake areas. Pink points represent the Asian Taklimakan desert and West African dust sources, yellow points represent the western Gobi desert in Asia and the Bodélé Depression in Africa, while orange points represent the eastern Gobi desert.

Asian deserts comprise a heterogeneous arid region (see e.g., Fig. 1 in either Sun et al., 2008 or Kurosaki and Mikami, 2007), which includes the well known Gobi desert, as well as the Taklimakan desert. On average, Asian deserts are found at higher elevations than African deserts, and the Taklimakan is entirely contained within the vast Tarim Basin, surrounded by $>3-\mathrm{km}$-high topography on all sides, except for a relatively small opening on the eastern boundary (see, e.g., Fig. 1 in Wiacek and Peter, 2009). In our study, the Gobi desert is sub-divided into two regions, each spanned by 42 points (Fig. 1). The peak of the Asian dust season for the Gobi desert occurs from March to May (e.g., Sun et al., 2001; Shao and Wang, 2003; Shao and Dong, 2006), while the Taklimakan, like Africa's Bodélé depression, is active nearly year-round, albeit with modest dust emission levels, peaking in spring and exhibiting a wintertime minimum. We examined night time total attenuated backscatter measurements made by the CALIPSO satellite (Winker et al., 2007) over the Tarim Basin from March to May 2007 (available on 42\% of days) and found that the basin is dusty nearly $100 \%$ of this time, with dust routinely reaching altitudes of $3-5 \mathrm{~km}$ above sea level. This is in good agreement with the groundbased observations of Wang et al. (2008), who also find that during spring the Tarim Basin has a much higher frequency of occurrence of floating dust events than the nearby Gobi desert. (The latter region, however, has a higher frequency of higher intensity events, which Wang et al., classify as "blowing dust" and "dust storms".) Finally, the CALIPSO-based work of Liu et al. (2008) also confirms our analysis and additionally shows that the Tarim Basin is dusty up to similar altitudes and in all months of the year except the winter months from December to February. The remote sensing measurements agree with balloon-borne measurements described by Iwasaka et al. (2003), wherein dust was clearly the major component of the coarse mode, as detected by electron microscope analyses of particles collected by an impactor, up to
$5 \mathrm{~km}$ over the eastern margin of the Tarim basin in August, 2002. Background summertime dust traced back to the Taklimakan desert was also detected by aircraft instrumentation and ground-based LIDAR over Japan (Matsuki et al., 2003).

\subsection{Characteristics of transport and ascent}

On account of its low source latitude $\left(15-30^{\circ} \mathrm{N}\right)$ Saharan dust is primarily transported westwards across the Atlantic, while Asian dust, which is sourced between 30$50^{\circ} \mathrm{N}$, is transported eastwards across the Pacific (e.g., Zender et al., 2003; Miller et al., 2006). Additionally, the longrange transport of African dust occurs primarily in the lowaltitude Saharan Air Layer (SAL) described by Karyampudi et al. (1999), while the long-range transport of Asian dust can be both low- and high-altitude $(<3 \mathrm{~km}$ and $>5 \mathrm{~km}$, respectively), depending critically on the relative location of dust emitting regions and synoptic scale weather systems, as shown by Tsai et al. (2008). Asian dust sources are preconditioned to reach higher regions of the troposphere by virtue of their higher elevation, which makes their surface potential temperature $(\sim 310-320 \mathrm{~K})$ comparable to that of the much hotter, but nearly sea-level-based African dust emitting regions. Additionally, Fig. 2 shows the global perspective on the increasing altitude of the $320 \mathrm{~K}$ potential temperature isentrope towards higher latitudes: air parcels directly above the surface of Asian dust emitting regions can reach higher neutral buoyancy levels by large-scale ascent mechanisms. We note that Fig. 2, as an annual and zonal mean of potential temperature, presents a much simplified view of vertical transport in the lower troposphere. In practice dry convection is also an important transport mechanism to consider, especially over the world's deserts (e.g., Cuesta et al., 2009). Finally, in the case of the Tarim basin in particular, the extreme topography likely plays a role in vertical transport, too, alternating between $\sim 1$ and $\sim 4-5 \mathrm{~km}$ over less than $100 \mathrm{~km}$ 


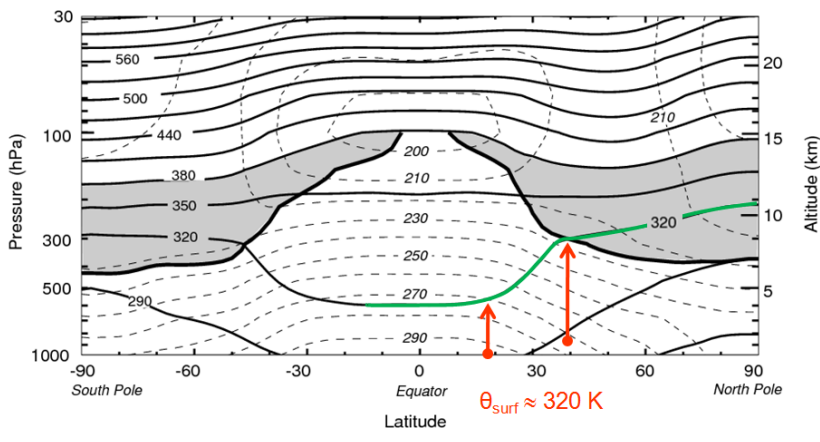

Fig. 2. Zonal and annual mean potential temperature (thin solid lines), absolute temperature (thin dashed lines), and tropopause (thick solid line). Shaded areas denote the lowermost stratosphere, whose potential temperature surfaces span the tropopause. Bases of red arrows mark the approximate latitude and altitude of African and Asian dust emission sources, which both reach surface potential temperatures of $\sim 320 \mathrm{~K}$. Figure adapted from Holton et al. (1995).

across parts of the Tian Shan mountain range, which forms the northern basin margin (see Fig. 1 of Wiacek and Peter, 2008). In general, dust from the Gobi desert is thought to be confined to $<3 \mathrm{~km}$ altitude $90 \%$ of the time, while dust from the Taklimakan desert is entrained relatively easily to $>5 \mathrm{~km}$ (Sun et al., 2001). We simulated a similar number of trajectories for two specific dust events in the Tarim Basin (May, 2007) and over West Africa (July, 2007) and found that while only $4.4 \%$ of African trajectories ascended to $450 \mathrm{hPa}$ ( $\sim 6-7 \mathrm{~km}), 96 \%$ of Asian trajectories ascended to the same pressure (see Wiacek et al. (2008) for details of these particular cases). Figure 3 shows this together with the predominant transport patterns; it is apparent that if African dust ascends to the upper troposphere, i.e., $<300 \mathrm{hPa}$, (Fig. 3a), this occurs near deep convective systems over or near the Atlantic, while dust from the Taklimakan desert (in the Tarim basin) seems at least partly influenced by the local topography, especially near the south and west basin margins (Fig. 3b, inset). The exact uplift mechanisms are complex and form the subject of ongoing research (e.g., Uno et al., 2005; Seino et al., 2005). Although Fig. 3 focuses on reaching the upper troposphere, we note that had trajectories been started near the top of the Saharan atmospheric boundary layer, routinely found at $\sim 5 \mathrm{~km}$ altitude, more transport at $\sim 500 \mathrm{hPa}$ would have been evident immediately in the African trajectories. However, both the melting level and the tropopause altitude above this low-latitude desert are correspondingly higher than in Asia and, moreover, satellite observations (e.g., Liu et al., 2007) show that the top of the dust layer at $\sim 5 \mathrm{~km}$ remains coherent in seasonal averages, capped by a persistent inversion, with no evidence of a slow "leakage" of dust to the upper troposphere.

\section{Methodology}

\subsection{Trajectory calculations}

In order to build a climatological understanding of potential interactions of Asian and African dust with clouds, we calculated four one-week (168-h) trajectories departing from each point in the given dust source regions (Fig. 1) at 00:00, 06:00, 12:00, and 18:00 on each day of 2007. All trajectories started from a uniform pressure of $770 \mathrm{hPa}$ (except those in Fig. 3, performed separately), chosen to correspond to $\sim 1-1.5 \mathrm{~km}$ height above the most elevated desert topography (in Asia). Trajectory variables of pressure $(p)$, temperature $(T)$, specific humidity $(Q)$, latitude and longitude were saved every $6 \mathrm{~h}$ (i.e., at 29 locations along each trajectory). We covered the dust source region of the Taklimakan desert, as defined by Tegen (2003) and coinciding with the Tarim Basin, with trajectory starting points distributed at $1^{\circ}$ horizontal resolution, yielding 42 points in total. Conveniently each of the five desert regions of interest (counting eastern and western Gobi regions separately) can be spanned roughly by 42 starting points, providing a constant number of trajectory points in each analysed region: $365 \times 4 \times 42 \times 29=1778280$. In order to best capture the complex wind patterns near the often rugged Asian desert topography, we used the highest resolution European Centre for Medium-Range Weather Forecasts (ECMWF) analysed wind, temperature and moisture fields available operationally (T799 in spectral space, 91 model levels, i.e. roughly $200 \mathrm{~m}$ vertical resolution in the lower troposphere). The ECMWF model uses a hybrid coordinate system that follows the terrain near the surface and relaxes to horizontal surfaces in higher model layers; there are $\sim 50$ model levels in the troposphere alone (Untch et al., 2006). The importance of model resolution, especially for the Tarim Basin, is highlighted by Tanaka and Chiba (2006), who describe how increasing the horizontal resolution from $\mathrm{T} 42$ $\left(\sim 2.8^{\circ}\right)$ to $\mathrm{T} 63\left(\sim 1.9^{\circ}\right)$ to $\mathrm{T} 106\left(\sim 1.1^{\circ}\right)$ changes the predicted dust column loading in their study from a non-event into a strong dust emission episode. The T799 (triangular truncation) spectral resolution analysis fields employed in our study correspond to $\sim 25 \mathrm{~km}$ horizontal resolution.

All trajectories were calculated using the LAGRangian trajectory ANalysis TOol (LAGRANTO) developed by Wernli and Davies (1997). This relies on the three components of the wind field, neglecting mixing, a limitation discussed below. In our modification, the ECMWF-derived specific humidity at each trajectory's starting point was subjected to the ambient temperature and pressure at the 28 trajectory points found downstream, thus providing "Lagrangian relative humidities" with respect to liquid water $\left(\mathrm{RH}_{\mathrm{w}}\right)$ and ice $\left(\mathrm{RH}_{\mathrm{i}}\right)$ along the trajectories and allowing to estimate the formation of liquid, mixed-phase and ice clouds downstream. The advantage of this approach is that we were able to decouple our analysis from the treatment of water condensation and ice nucleation employed in the ECMWF model. In particular, 


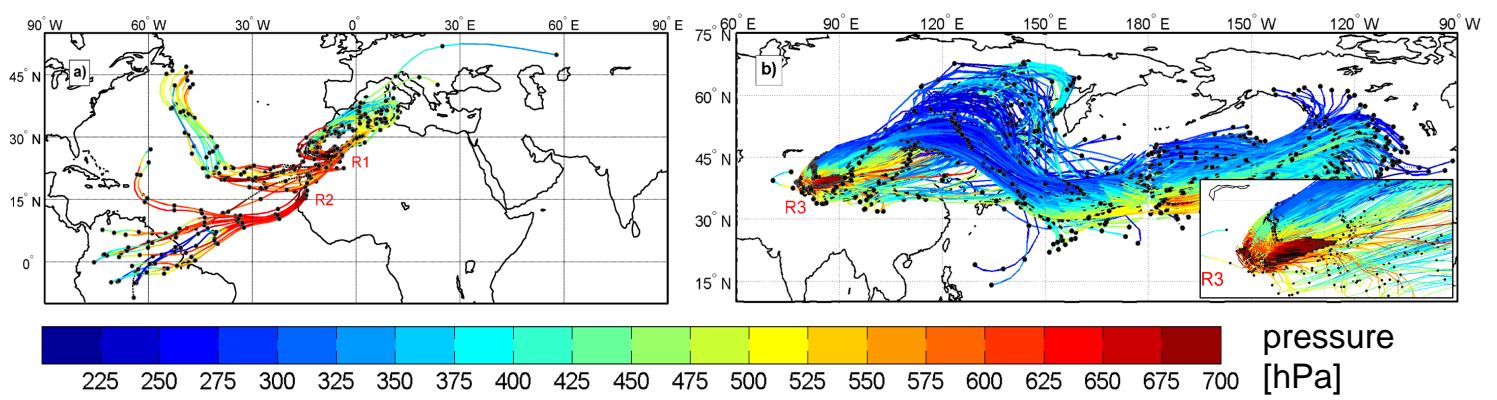

Fig. 3. Trajectories started from $700 \mathrm{hPa}$ in African dust plume regions $\mathrm{R} 1$ and $\mathrm{R} 2$ (a) and in Asian dust plume region R3 (b) that ascended to altitudes above the $450-\mathrm{hPa}$ level. Black dots indicate trajectory locations at $24-\mathrm{h}$ intervals while color along a trajectory indicates its pressure $(\mathrm{hPa})$.

we were able to simulate conditions of ice supersaturation along our trajectories, which are not presently represented in ECMWF analyses fields (supersaturation is allowed to develop in forecast fields, but always from non-supersaturated initial analysis values, see Tompkins et al., 2007).

\subsection{Limitations}

Our calculated trajectories are simple transport trajectories without microphysical simulation of either dust emission or wet or dry deposition processes. Regarding the latter, where our objective is to identify the availability of deposition IN in cirrus-forming regions, we look for conditions of subsaturation with respect to water, making wet deposition irrelevant. Where we examine trajectory points that have experienced water saturation, we discuss possible effects of wet deposition by in-cloud scavenging. Regarding dry deposition, we calculated the terminal velocity of mineral dust particles likely to make it to the upper troposphere, i.e., particle radius of $1 \mu \mathrm{m}$ or less with a density of $2.65 \mathrm{~g} / \mathrm{cm}^{3}$ and an aspect ratio of $1: 3$, to be less than $40 \mathrm{~m} /$ day for suspension altitudes $<10 \mathrm{~km}$. On the one-week time scale of our trajectory calculations, this amounts to only $280 \mathrm{~m}$ of descent by sedimentation. While we are also neglecting turbulent deposition near the surface, total dry deposition (turbulent and by sedimentation) does not play a prominent role along our oneweek trajectories for micrometer-sized particles. Nonetheless, it would not be correct to assume that the trajectories will be dust-bearing at all times. Based on the dust seasonality discussion presented in Sect. 2, Taklimakan transport trajectories are most representative of dust-laden air masses in spring and, to some extent, also in summer and fall, while Gobi transport trajectories are most dust-representative during March, April and May. In contrast, West African trajectories can be assumed to carry dust from May to August, and Bodélé trajectories in winter, as well as in spring and fall, with a reduction in the summer months.

A more serious drawback of our approach is that we neglect mixing processes, which may influence our calculated "transported" or "Lagrangian" relative humidities. However, wind-blown dust from the Taklimakan often rises in parcels of very hot and dry air (e.g., $30^{\circ} \mathrm{C}$ at $4 \% \mathrm{RH}$ ) such that mixing with air from surrounding less arid regions will generally result in a moistening effect. Generally, air above deserts is extremely dry because it has undergone strong subsidence or orographic lift and precipitation in upstream mountains. As such, desert soils lose humidity to the atmosphere, and this may lead to a very limited moistening of the air. Only when dust-laden air parcels start leaving the desert regions does mixing with much more humid air parcels lead to a substantial moistening. For example, the dust-laden air can be entrained into (deep) convection, which may transport the dust vertically all the way to the tropopause. However, this will inevitably lead to air in these mixed parcels undergoing washout and becoming incapable of reaching cirrus levels unprocessed. Therefore, neglect of mixing in our analysis is indeed a conservative approximation, and the estimated fraction of dusty, unprocessed air reaching cirrus levels may, if anything, be somewhat overestimated.

Another limitation is that our trajectories, though high in resolution, do not resolve small-scale convection. While Koch and Renno (2005) showed that convective plumes and vortices may contribute up to about $35 \%$ of the global budget of mineral dust, their work was related to small-scale, dry processes in the boundary layer, without a direct mechanism of transport to the upper troposphere. A related issue is that of unresolved dry convection in the deep Saharan boundary layer routinely reaching altitudes of $5 \mathrm{~km}(\sim 500 \mathrm{hPa})$, while our trajectories always originate at $770 \mathrm{hPa}(\sim 2 \mathrm{~km})$. The lower boundary layer was chosen to ensure that trajectories originate from within the boundary layer throughout the diurnal cycle and also to better justify our assumption that trajectories contain dust available for long-range transport during peak dust emission seasons. However, trajectories launched from various heights would be interesting to examine, especially in the complex and deep Saharan atmospheric boundary layer (see, e.g., Knippertz et al., 2009). Although boundary layer height is a parameter routinely analyzed by ECMWF, its accuracy is difficult to evaluate at this time given the notorious lack of observations in remote dust 
source regions. Recognizing the care necessary in sampling multiple altitudes in the boundary layer, we choose to limit the scope of our study at this stage to more reliably dusty and diurnally unaffected lower regions of the boundary layer.

Deep moist convection, e.g., in large-scale weather systems that involve anvil cirrus formation, is also not well resolved by our trajectories, even though aircraft observations between 5 and $15 \mathrm{~km}$ have documented such transport of dust to the upper troposphere (Cziczo et al., 2004a). This convection is accompanied by large supersaturations with respect to water, likely to either nucleate ice on the best dust IN and thus cause their rapid sedimentation, or likely to coat mediocre dust IN with water and soluble species, and thus convert them from deposition to immersion IN or deactivate them altogether. Finally, the efficiency of dust IN released from evaporating ice crystals at convective outflow levels may vary greatly. While laboratory evidence suggests that the efficiency of mineral dust IN subjected to repeated cycles of ice nucleation increases (Mason and Maybank, 1958; Roberts and Hallett, 1968; Knopf and Koop, 2006), the presence of substances other than water, e.g., sulphuric acid, is found to have neutral to negative effects on the ice nucleation efficiency of dust IN (Archuleta et al., 2005; Knopf and Koop, 2006; Eastwood et al., 2009). Additionally, coatings of ammonium sulphate (an inorganic salt) are found to inhibit ice nucleation at higher temperatures while increasing IN efficiency at temperatures below the ammonium sulphate efflorescence point (Eastwood et al., 2009). Moreover, the introduction of organic substances in cloud processing may further complicate the situation, as field measurements have shown that organic-rich particles preferentially remain unfrozen in homogeneous nucleation processes (Cziczo et al., 2004b), and, more recently, Möhler et al. (2008) have shown with laboratory experiments that secondary organic coatings markedly suppress the ice nucleation efficiency of mineral dust IN at cirrus temperatures. As our goal is to assess the availability of bare mineral dust deposition IN in cirrus-forming regions, the inability to fully resolve (deep) convection is neglected in the following, i.e. we do not follow up on the possibility that dust particles, after passing the "tropical convective dust pump" may be re-released as potentially still potent, or even pre-activated ice nuclei. Since deep convection is relatively more important than synoptic scale ascent in the tropics (as opposed to mid-latitudes), this may be a source of bias.

Finally, in the non-convective transport occurring along our trajectories over seven days we neglect aerosol aging and the formation of chemical coatings, if any. This is well justified for dusts emitted from Africa, which are transported across pristine Atlantic Ocean regions, and have been found to contain little sulphate, nitrate or organic coatings after a week of transport to the Florida region (Cziczo et al., 2004a). Chemical coatings may also be neglected for dust trajectories originating from the Taklimakan desert, which tend to travel at altitudes considerably above the polluted Asian planetary boundary layer (see Sect. 2.2). It is only for dust originating from the Gobi desert, which is often transported towards the Pacific coast at relatively low altitudes, that neglecting chemical aging processes could become important.

\subsection{Data analysis}

For each dust emission region, a set of $\sim 1.8$ million calculated trajectory points was sorted according to their Lagrangian relative humidity and temperature into (i) water clouds (below formally cloud type WATER, $T>0{ }^{\circ} \mathrm{C}$ ), (ii) mixed-phase clouds (below formally cloud type MPC, $-40^{\circ} \mathrm{C} \lesssim T<0^{\circ} \mathrm{C}$ ), and (iii) cirrus clouds (below formally cloud type CIRRUS, $T \lesssim-40^{\circ} \mathrm{C}$ ); see Fig. 4 for Roman numerals representing the cloud types discussed here. (We note that $-40^{\circ} \mathrm{C}$ is formally too cold to be considered a mixed-phase cloud, however, a sensitivity test performed at $-36^{\circ} \mathrm{C}$ shows that our conclusions are not strongly affected by the choice of this transition temperature.) Additionally, ice-supersaturated and simultaneously watersubsaturated regions were tracked and classified as cloud types (iv) COLD_HET $\left(T \lesssim-40^{\circ} \mathrm{C}\right)$ and (v) WARM_HET $\left(-40^{\circ} \mathrm{C} \lesssim T<0^{\circ} \mathrm{C}\right)$, on account of the potential of potent IN to cause heterogeneous ice nucleation in these regions, before the trajectories reach conditions suitable for CIRRUS clouds (by virtue of homogeneous freezing) or MPC clouds (by virtue of water saturation), respectively. COLD_HET clouds comprise purely heterogeneously nucleated, optically thin and cold ice clouds. They are distinct from our cloud type CIRRUS, which we reserve for clouds that are homogeneously nucleated at $T \lesssim-40{ }^{\circ} \mathrm{C}$, i.e., "classical", optically thick cirrus clouds. WARM_HET clouds comprise heterogeneously nucleated, likely optically thin, pure ice clouds that form entirely in the absence of liquid water, like "classical" cirrus, but whose nucleation temperatures are much warmer than "classical" cirrus. Although we postulate WARM_HET clouds, there are limitations (discussed below) to the activity of heterogeneous IN below water saturation at the warmest sub-zero temperatures and lowest ice supersaturations of region (v). Finally, region (vi) of Fig. 4 comprises those points that were classified as clear air.

The bottom panel of Fig. 4 shows, for each dust emission region, the number of trajectories that reach water saturation for a given temperature. The initial moisture content of trajectories leaving the Asian deserts is such that the majority of those air parcels that are suitable for cloud formation reach water saturation for mixed-phase cloud temperatures $\left(-40^{\circ} \mathrm{C} \lesssim T<0^{\circ} \mathrm{C}\right)$. This is similar for the African trajectories, however, there is much more variability throughout the year. In the more southerly Bodélé region in particular, a distinct (summer) wet season is responsible for the secondary peak of "wet" trajectories centred around $280 \mathrm{~K}$.

Finally, the transport history of each trajectory point was also recognized, leading to three additional cloud types, described below. Again following the top panel of Fig. 4, the 


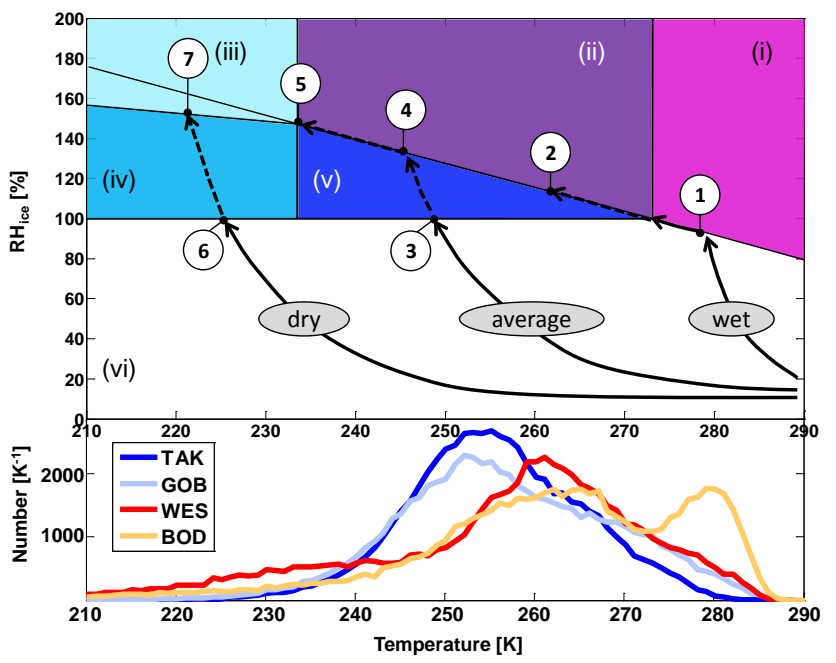

Fig. 4. Schematic of cloud types (Roman numerals: (i) water, (ii) mixed-phase, (iii) cirrus, (iv) COLD_HET, (v) WARM_HET, (vi) clear sky) and cloud formation processes (Arabic numerals: (1) WATER, (2) MPC', (3) WARM_HET, (4) MPC, (5) CIRRUS', (6) COLD_HET, (7) CIRRUS) possible along the air parcel trajectories, depending on a schematically indicated initial moisture content ("wet", "average", "dry"). Straight line containing (1) and (5) approximates $\mathrm{RH}_{\mathrm{W}}=100 \%$ (for simplicity extrapolated to $T>273 \mathrm{~K}$ ). Straight line separating colored regions (iii) and (iv) follows the parameterization of Koop et al. (2000) for $200 \mathrm{~nm}$ solution droplets. Bottom panel shows the distribution of water saturation temperatures of individual trajectories, given their actual initial moisture content. See text for details.

Arabic numerals denote specific cloud formation processes that can occur upon lifting and cooling for "wet", "average" and "dry" trajectories, referring to a theoretical initial moisture content at trajectory time $t=0$. As a "wet" trajectory lifts and cools, it reaches water saturation and forms WATER clouds (1), where from here on we use capital letters to distinguish a cloud type specific to our study from the generic use of the word, possibly followed by mixed-phase cloud formation (2) in the event of further lifting and cooling. The most common ("average") trajectory passes region (v) as it rises and cools, where ice can nucleate WARM_HET clouds heterogeneously in the presence of potent IN (3), before reaching water saturation and mixed-phase cloud formation (4), possibly followed by homogeneous nucleation of CIRRUS clouds (5) upon further lifting and cooling. The "dry" trajectory passes region (iv), where heterogeneous nucleation of COLD_HET clouds is possible (6), before reaching the homogeneous ice nucleation limit and CIRRUS formation (7). We define three additional cloud types to fully account for a trajectory point's history as follows. While process (4) leads to mixed-phase cloud type MPC, process (2) leads to what we call mixed-phase cloud type MPC', on account of the prior formation of a WATER cloud at $T>0{ }^{\circ} \mathrm{C}$ in the trajectory. Analogously, while process (7) leads to CIRRUS clouds, process (5) leads to what we call CIRRUS', on account of prior formation of an MPC in the trajectory. Finally, (not shown in Fig. 4), we classify some trajectories as CIRRUS", on account of prior formation of a WATER cloud in the trajectory, also at $T>0{ }^{\circ} \mathrm{C}$.

\section{Results and discussion}

\subsection{Dust/Cloud interactions by cloud type and dust region}

\subsubsection{General effects}

Of the $\sim 1.8$ million trajectory points (as opposed to entire trajectories, which contain 29 points each) originating from each region, the vast majority were clear sky points (Table 1 ), which is consistent with the source regions being deserts. The percentage of clear sky points originating from Asian deserts $(\sim 60 \%)$ is smaller than that from African deserts $(\sim 85 \%)$, although nearly half of this difference may be due to the higher number of "crashed" points originating from Asian dust emitting regions. "Crashed" points correspond to those portions of trajectories whose computation was terminated on account of contact with the surrounding topography, and which were subsequently replaced with numeric fill values from the point of surface contact onwards. Clear sky points combined with crashed points comprise $\sim 70 \%$ of Asian and $\sim 85 \%$ of African points. If an air parcel (a trajectory point in our analysis) that was initially clear sky experienced ascent and cloud formation, followed by descent and cloud evaporation, this second occurrence of clear sky was classified separately as "oscillatory clear sky", on account of the uncertain fate of any dust particles potentially carried by the air parcels during the intervening cloud processing (which we do not explicitly model). Any subsequent cycles of clear sky following another cloud formation event were also grouped into this "oscillatory clear sky" type. Finally, if an air parcel was classified as cloudy at $t=0$, any subsequent incidence of clear sky was also grouped into the "oscillatory clear sky" type. In other words, we keep track of whether or not a clear sky trajectory point was always a clear sky trajectory point in order to understand if wet scavenging could have already affected the air parcel and removed any dust potentially found in it. The remaining trajectory points were classified as either cloudy or "oscillatory cloudy", with the latter type accounting for repeated cloud formation in a trajectory (analogous to repeated clear sky recurrence) and the associated oscillations of an air parcel about either ice saturation or water saturation, or both. A trajectory point classified as cloudy was permitted to have zero or one occurrence of clear sky upstream, i.e., it could start as either clear or cloudy at $t=0$. Counted in this way, all cloudy, "oscillatory cloudy", clear sky and "oscillatory clear sky" points add up to $365 \times 4 \times 42 \times 29=1778280$ points. 
Table 1. Percentage of the $\sim 1.8$ million trajectory points originating from each dust emission region that were classified as crashed (contact with orography), clear sky (type vi in Fig. 4), cloudy (sum of types $\mathrm{i}-\mathrm{v}$ ), or "oscillatory" (multiple entry into any of types i-vi, see text for details).

\begin{tabular}{lrrrr}
\hline & Taklimakan & Gobi & West Africa & Bodélé \\
\hline Crashed & 13.0 & 8.9 & 0.4 & 0.3 \\
Clear sky & 57.3 & 57.6 & 84.5 & 86.5 \\
Oscillatory Clear Sky & 7.7 & 11.0 & 5.7 & 2.7 \\
Cloudy & 13.4 & 15.2 & 6.9 & 7.6 \\
Oscillatory Cloudy & 8.5 & 7.4 & 2.6 & 3.0 \\
\hline
\end{tabular}

The sum of cloud types (i-v) introduced in Sect. 3.3 (Fig. 4) together with cloud types MPC', CIRRUS', and CIRRUS" comprises $13.4 \%$ of points originating from the Taklimakan, $15.2 \%$ from the Gobi, $6.9 \%$ from West African deserts and $7.6 \%$ from the Bodélé Depression. Given that Asian trajectories have a lower initial moisture content (not shown) and are subject to water saturation at predominantly lower temperatures (bottom panel of Fig. 4), the higher incidence of cloudiness in Asian trajectories is explained by higher ascent from this region as compared to Africa (see details in Sect. 4.3). The detailed breakdown into various cloud types is shown in Fig. 5 and in Table 2, including "oscillatory" cloudiness, denoted by the suffix "OSC". The occurrence of cloud types CIRRUS and COLD_HET (homogeneously and heterogeneously formed pure ice clouds at "classical" cirrus temperatures of $T \lesssim-40{ }^{\circ} \mathrm{C}$, respectively) is negligible in all regions $(<0.025 \%$ of trajectory points in any region). The potential for mineral dust interactions with the remainder of cold cloud types (CIRRUS', CIRRUS", MPC and WARM_HET, excluding only MPC') is greater from Asian than from African dust sources by roughly a factor of 2. MPC' points are those that experience water saturation for $T>0{ }^{\circ} \mathrm{C}$, which is more likely to occur in the warmer African deserts. Results are numerically similar in the two Asian regions and again in the two African regions. By far, the potential influence of mineral dust is greatest via MPC clouds, followed by CIRRUS' (cirrus clouds possibly forming subsequent to MPC glaciation, after further lifting and cooling of air parcels), and lastly via WARM_HET clouds (heterogeneously formed, likely to be optically thin, relatively warm, pure ice clouds). We note again that the most prominent component of the cirrus cloud family in all geographic regions is in fact CIRRUS', i.e., those cirrus clouds that formed after the air parcel experienced water saturation at some $-40{ }^{\circ} \mathrm{C}<T<0^{\circ} \mathrm{C}$ and continued rising to "classical" cirrus-forming regions. CIRRUS", i.e. those cirrus clouds that possibly formed after the air parcel experienced water saturation for $T>0{ }^{\circ} \mathrm{C}$, make only a small contribution to the cirrus family, along with "oscillatory cirrus". Finally, on an

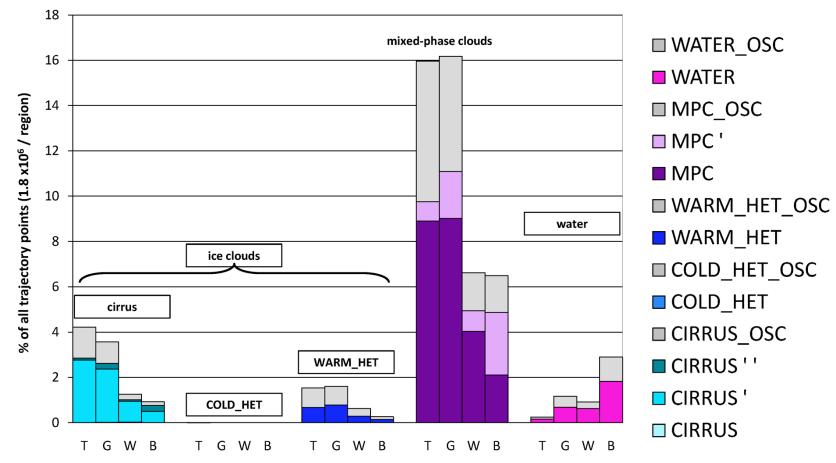

Fig. 5. The breakdown of only those trajectory points classified as cloudy in each geographic region (i.e. sum of last two lines in Table 1): Taklimakan (T), Gobi (G), West Africa (W) and Bodélé (B). Note that cloud types CIRRUS, COLD_HET and COLD_HET_OSC are not visible on this scale. See Table 2 for tabular format.

annual basis, the potential for mineral dust to affect warm WATER clouds is lowest in all geographic regions except the Bodélé. The Taklimakan desert leads to the least WATER cloud points, the Gobi and West African deserts are cloudier and comparable to one another, while the Bodélé gives three times more WATER cloud points than the latter two (Table 2).

\subsubsection{Seasonal effects in WATER clouds}

Figure 6 shows the monthly breakdown of trajectory points originating from the four dust source regions for all cloud types excluding COLD_HET because it is negligible, as mentioned above, but including all "oscillatory cloud" types (again shown in grey). The detailed cloud type color scheme is identical to Fig. 5. Note that the occurrence of all cloud types peaks outside of the winter months (DJF), during which our transport trajectories are least representative of dustbearing trajectories, as discussed in Sect. 2.1, with the exception of the Bodélé region, which is most active in DJF. WATER clouds peak during the summer months, as expected. Although mineral dust particles are large-sized, their role in the formation of WATER clouds is negligible as compared to the ubiquitous presence of soluble aerosols, which are much more likely to activate into cloud droplets first (e.g., Herich et al., 2009). Nonetheless, dust particles can develop partial or full water or solution coatings at this stage (e.g. containing ammonium sulfate or organics), which would conceivably deteriorate their efficiency in serving as contact or deposition ice nuclei (Pruppacher and Klett, 1997) in the secondary cloud type MPC' or perhaps even as deposition IN in CIRRUS", discussed below. Increasing the uncertainty, some IN can also be removed by below-cloud scavenging (if not by incloud nucleation scavenging) and thus not be present at all in MPC' or CIRRUS" clouds. In a recent modelling study Croft et al. (2010) suggest that the global and annual mean dust mass removal from the atmosphere is primarily by in-cloud 
scavenging (involving both cloud droplets and ice crystals, $34 \%$ ) and sedimentation (36\%), with below-cloud scavenging and turbulent dry deposition accounting for $24 \%$ and $6 \%$, respectively. For that same study, the role of in-cloud and below-cloud scavenging of the insoluble dust mass in the accumulation size mode (radius $50-500 \mathrm{~nm}$, most relevant to our study as discussed in Sect. 3.2) grows to $56 \%$ and $36 \%$, respectively (B. Croft, personal communication, 2010); however, since a large fraction of cloud droplets and precipitation evaporates before reaching the surface, the fate of mineral dust processed in liquid water clouds remains very uncertain.

\subsubsection{Seasonal effects and temperature details of MPC clouds}

Figure 6 shows that the potentially most affected cloud type, MPC, also peaks during the summer, and is about twice as likely to result from Asian trajectories as from African trajectories (Fig. 5). The role of mineral dust in the colder MPC cltion. Figure 7 (panels A, B, C and D) ouds is expected to be much more pronounced than in WATER clouds, i.e., by causing faster glaciashows that the distribution of water saturation temperatures corresponding to the initial moisture content of our MPC trajectory points is mostly warmer than $-20^{\circ} \mathrm{C}$ in all geographic regions. At these relatively warm temperatures, it is possible for dust to participate in contact nucleation (e.g., Pitter and Pruppacher, 1973; Hobbs and Rangno, 1985; Diehl et al., 2006). Several laboratory studies show dust to be active as a condensation/immersion mode IN for $T<-10^{\circ} \mathrm{C}$ (Mason and Maybank, 1958; Bailey and Hallett, 2002; Zimmermann et al., 2008). For the minority of MPC points in Fig. 7 (panels A-D) with water saturation roughly between $-40^{\circ} \mathrm{C}<T<-20^{\circ} \mathrm{C}$, condensation/immersion along with deposition should be more efficient than at warmer temperatures (Hoffer, 1961; Field et al., 2006; Kanji and Abbatt, 2006; Eastwood et al., 2009; Welti et al., 2009). These results are consistent with Fig. 4 (bottom panel), which shows that the moisture content of the vast majority of whole trajectories in all geographic regions is such as to lead to water condensation for $-40^{\circ} \mathrm{C}<T<0^{\circ} \mathrm{C}$ and hence to maximize the impact of dust on mixed-phased clouds. Nonetheless, the exact fraction of MPC, MPC' and MPC_OSC clouds in our study should be treated with some caution due to our neglect of both mixing and condensation along the trajectories. Also worth noting is that trajectory points reaching the mixed-phase cloud phase space (ii) of Fig. 4 must pass through the ice-saturated WARM_HET cloud region (v), where the most efficient dust IN may have already been activated in deposition mode, thus eliminating these particles from participation in MPC cloud formation, as discussed next.

\subsubsection{Seasonal effects and $\mathrm{T}-\mathrm{RH}_{i}$ details of WARM_HET clouds}

Figure 6 shows conditions favourable for WARM_HET clouds in the Asian Taklimakan region to occur with highest frequency during spring (MAM), but also during the summer (JJA) and fall (SON), coinciding exactly with the peak of dustiness in the Tarim basin (Sect. 2.1). In the Asian Gobi desert, conditions favourable for WARM_HET clouds occur in MAM, but there is a JJA minimum, followed by an increase not only in SON, but also DJF, when dustiness is suppressed in the region due to snow cover. The summer minimum in WARM_HET cloud occurrence (most pronounced in the Gobi region) is likely a trade off with the increased occurrence of warmer temperature WATER clouds and secondary MPC' clouds. Outside of JJA, conditions favourable for WARM_HET clouds appear throughout the year likely because there is always enough moisture to guarantee ice saturation after trajectory lifting and cooling, whereas water saturation conditions necessary for WATER and MPC' clouds are harder to fulfil. In the African deserts, conditions favourable for WARM_HET clouds are about half as likely to occur throughout the year (Table 2 and Fig. 6). In the West African region, WARM_HET clouds are potentially at a minimum in JJA, which is the peak of the dust emission season. In the Bodélé, there is potentially a better coincidence with the dust source activity occurring in MAM and SON, but not with the peak in DJF. The possibility of these warm temperature pure ice clouds appearing before (below) mixed-phase clouds is not clear. Figure 7 (panels I, J, K and L) shows that in Asian regions WARM_HET clouds potentially occur with the highest frequency for $\mathrm{RH}_{\mathrm{i}}<110 \%$ and $T>-20^{\circ} \mathrm{C}$, where deposition freezing is "generally" not observed in laboratory studies (Field et al., 2006); however, a large number of events also occurs for higher $\mathrm{RH}_{\mathrm{i}}$ and lower $T$ combinations, where deposition freezing is more efficient (Knopf and Koop, 2006), especially for larger particles (Zimmermann et al., 2008) and longer exposure times (Kanji and Abbatt, 2006). In fact, the integral over $\mathrm{RH}_{\mathrm{i}}$ from panels IL of Fig. 7 (shown in panels E, F, G, H) displays a peak at $-18^{\circ} \mathrm{C}$ for the Asian dust regions, highlighting the fact that the colder temperature WARM_HET points are as numerous as the warmer temperature points, but spread out over a larger range of $\mathrm{RH}_{\mathrm{i}}$ in panels I-L. Finally, the predicted frequency of occurrence of WARM_HET clouds potentially originating from African regions is consistently lower than from Asian regions, and it is restricted to warmer temperatures, which are thought to be even less favourable to heterogeneous ice formation. We will return to this discussion after describing the remaining cloud types. 

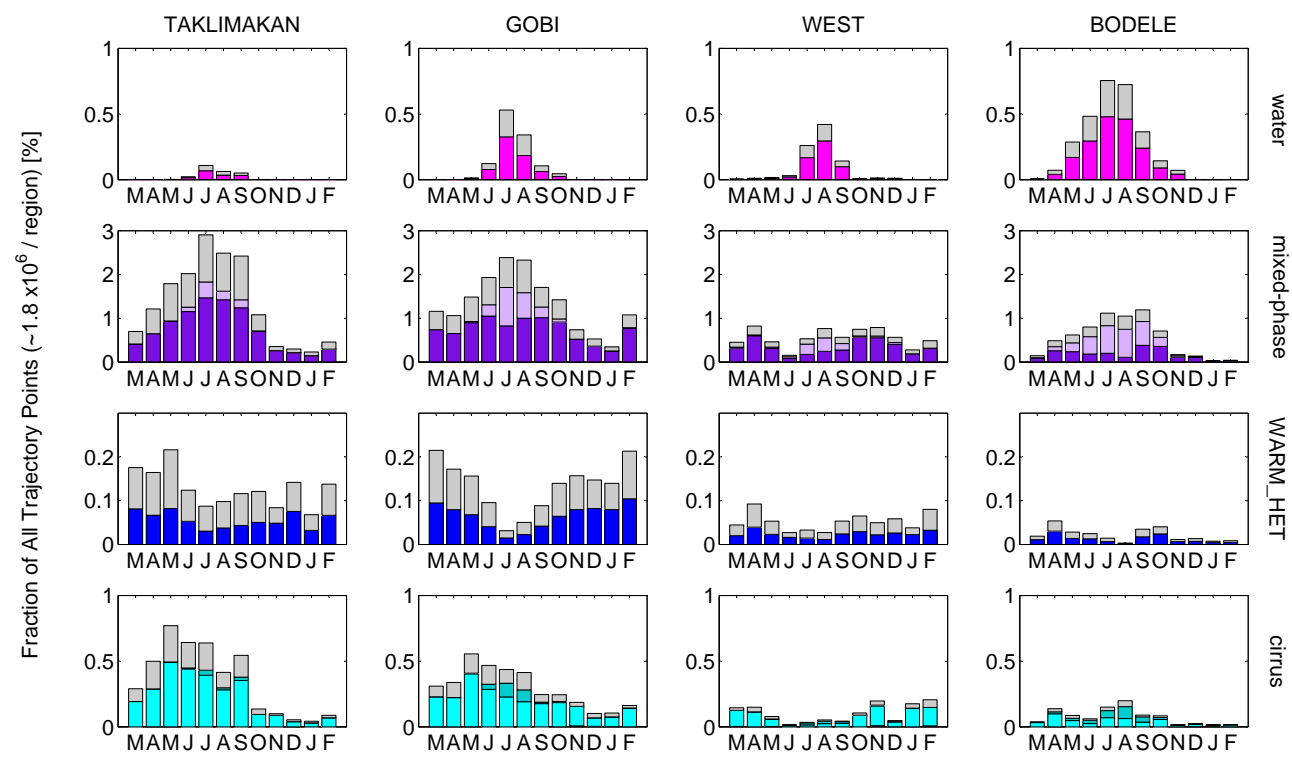

Fig. 6. Monthly breakdown of cloudy trajectory points in each geographic region (by column) and by cloud type (by row, as labelled, with details of cloud sub-types identified by color as in Fig. 5). COLD_HET clouds are not shown.

\subsubsection{Seasonal effects and temperature details of other ice clouds}

In contrast to WARM_HET, the COLD_HET cloud type is not shown in Fig. 6 because less than 42 points fall into it in any region $(<8$ in the Taklimakan). Similarly, the CIRRUS cloud type comprises $<437$ trajectory points in any region ( $<28$ in the Taklimakan). Much more numerous (in fact the second most numerous of all non-oscillatory cloud types, except WATER in the seasonally moist Bodélé region) is the related CIRRUS' type (Table 2 and Fig. 6), with CIRRUS" and CIRRUS_OSC comprising the small remainder of all our cirrus types. As was the case with other cloud types in Fig. 6, the occurrence of CIRRUS' clouds peaks away from DJF, which is a time of low dust emission, except in the Bodélé; furthermore, CIRRUS' occur more frequently from Asian deserts than from African deserts. CIRRUS' points correspond to air parcels that reached the cirrus temperature regime only after first experiencing water saturation in mixed-phase clouds. Figure 7 (panels E, F, G and $\mathrm{H})$ shows that the water saturation temperature for the MPC clouds that precede any subsequent CIRRUS' clouds (obtained after further lifting and cooling) peaks around $-20^{\circ} \mathrm{C}$ for the Asian deserts. However, given the distribution of saturation temperatures, it is reasonable to argue that a substantial fraction of dust IN stay inactive during MPC formation at $T>-20^{\circ} \mathrm{C}$. They might either remain interstitial (becoming available as deposition IN during a subsequent CIRRUS' formation event), or perhaps even transform into some preactivated form after liquid phase processing (e.g., becoming immersion nuclei, see discussion in Sect. 3.2). Laboratory studies show mixed results for pre-activation effects on min- eral dust (Möhler et al., 2006; Knopf and Koop, 2006), although variable particle size may be an important confounding factor between studies. The West African region displays a similar distribution of water saturation temperatures for MPC clouds preceding CIRRUS', however, the number of CIRRUS' points themselves is smaller by a factor of 2 3. Lastly, in the Bodélé region the MPC cloud saturation temperatures are warmest of all, implying that most of the dust IN could survive nucleation scavenging in these mixedphase clouds by remaining interstitial; however, the number of CIRRUS' points originating from this geographic region is again small. In all geographic regions, IN would not only be lost to nucleation scavenging, but also via below-cloud scavenging, further reducing the availability of processed/preactivated IN for subsequent CIRRUS' formation. Finally, we note that as with other models of its kind, ECMWF meteorological analyses do not resolve, but rather parameterize small-scale convective mass transfer. Although there is evidence of very fast trajectory ascent in convective systems over the Atlantic in Fig. 3a, clearly our trajectory analysis cannot fully resolve dust transported convectively to the upper troposphere, as was shown to be the case for African dust near Florida by Cziczo et al. (2004a). Dust transported in this manner would enhance the CIRRUS' and CIRRUS" type but not change our overall conclusions about the lack of unprocessed IN for CIRRUS formation, and the prevalence of dust interactions with mixed-phase clouds.

\subsubsection{Discussion}

We showed, using trajectory modelling and ECMWF specific humidity data, the large potential for interactions between 
Table 2. Breakdown of cloudy trajectory points in each region (last two lines in Table 1) as a percent fraction of all trajectory points in each region $\left(\sim 1.8 \times 10^{6}\right)$. (This is Fig. 5 , in table form.)

\begin{tabular}{|c|c|c|c|c|c|}
\hline Cloud Type & Description & Taklimakan & Gobi & West Africa & Bodélé \\
\hline WATER & $\mathrm{RH}_{\mathrm{W}}>100 \%, T>0{ }^{\circ} \mathrm{C}$ & 0.15 & 0.68 & 0.62 & 1.82 \\
\hline WATER_OSC & Oscillatory - see Sect. 4.1.1 & 0.09 & 0.48 & 0.30 & 1.08 \\
\hline MPC & $\mathrm{RH}_{\mathrm{W}}>100 \%,-40^{\circ} \mathrm{C}<T<0^{\circ} \mathrm{C}$ & 8.90 & 9.01 & 4.04 & 2.10 \\
\hline MPC' & Like MPC, but experienced WATER conditions first & 0.85 & 2.08 & 0.91 & 2.76 \\
\hline MPC_OSC & Oscillatory - see Sect. 4.1 .1 & 6.21 & 5.09 & 1.68 & 1.63 \\
\hline WARM_HET & $\mathrm{RH}_{\mathrm{i}}>100 \%, \mathrm{RH}_{\mathrm{W}}<100 \%,-40^{\circ} \mathrm{C}<T<0^{\circ} \mathrm{C}$ & 0.67 & 0.77 & 0.28 & 0.14 \\
\hline WARM_HET_OSC & Oscillatory - see Sect. 4.1.1 & 0.87 & 0.83 & 0.34 & 0.12 \\
\hline COLD_HET & $100 \%<\mathrm{RH}_{\mathrm{i}}<$ homogeneous nucleation limit, $T<-40^{\circ} \mathrm{C}$ & 0.00 & 0.00 & 0.00 & 0.00 \\
\hline COLD_HET_OSC & Oscillatory - see Sect. 4.1.1 & 0.00 & 0.00 & 0.00 & 0.00 \\
\hline CIRRUS & $\mathrm{RH}_{\mathrm{i}}>$ homogeneous nucleation limit, $T<-40^{\circ} \mathrm{C}$ & 0.00 & 0.02 & 0.02 & 0.01 \\
\hline CIRRUS' & Like CIRRUS, but experienced MPC conditions first & 2.76 & 2.35 & 0.92 & 0.49 \\
\hline CIRRUS" & Like CIRRUS, but experienced WATER and MPC conditions first & 0.09 & 0.26 & 0.06 & 0.26 \\
\hline CIRRUS_OSC & Oscillatory - see Sect. 4.1.1 & 1.37 & 0.95 & 0.24 & 0.17 \\
\hline
\end{tabular}
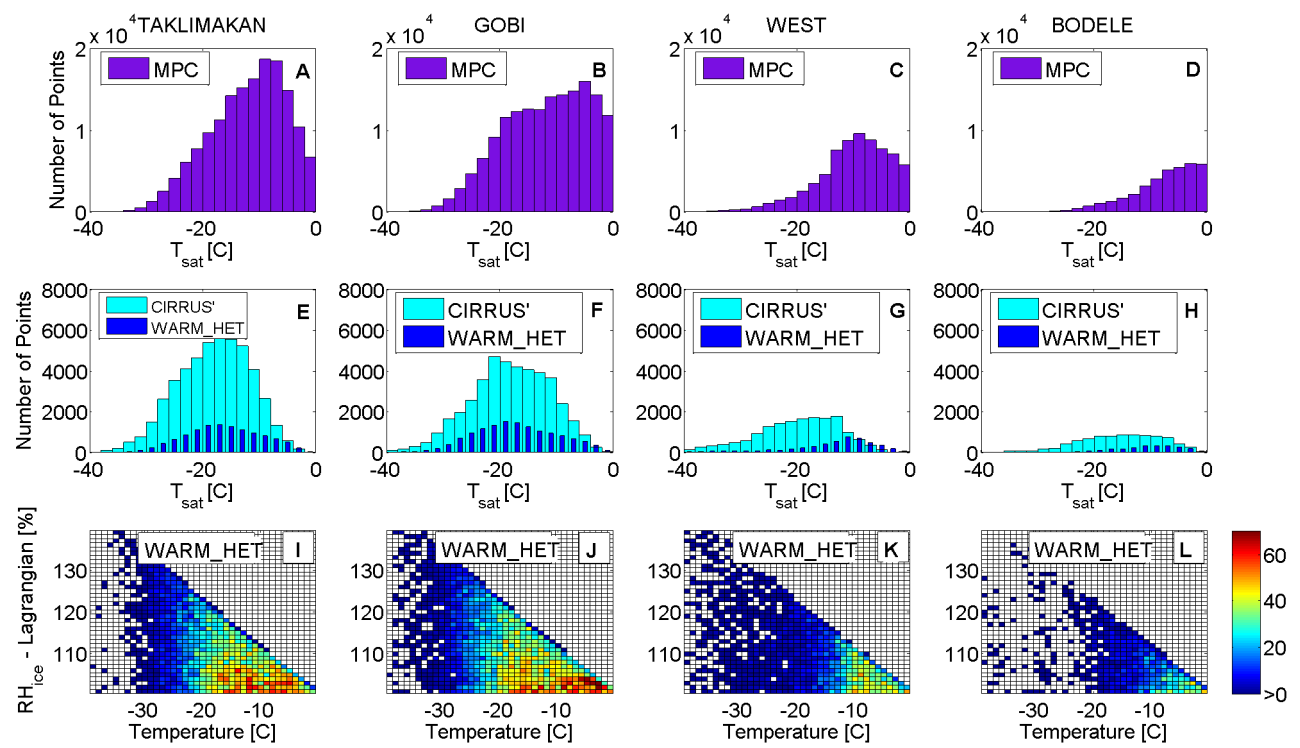

Fig. 7. Distribution of temperature at water saturation for trajectory points classified as MPC (A, B, C, D) and CIRRUS' (E, F, G, H) clouds. Frequency of occurrence of WARM_HET cloud points $(\mathbf{I}, \mathbf{J}, \mathbf{K}, \mathbf{L})$ in the $\mathrm{RH}_{\mathrm{i}}$ vs. $T$ space, whose integral over $\mathrm{RH}_{\mathrm{i}}$ is shown in $(\mathrm{E}, \mathrm{F}, \mathrm{G}, \mathrm{H})$ using the $T_{\text {sat }}$ axis for brevity. Each geographic region is shown in a separate column, as labelled.

mineral dust and mixed-phase clouds, as well as a nonnegligible potential for dust IN mediating the formation of relatively warm, pure ice clouds (WARM_HET), which, if they occur at all, we predict to be found in air parcels prior to the formation of mixed-phase clouds (below their cloud base). We found the potential for unprocessed/uncoated dust to affect "classical" cirrus-forming regions to be negligible, with interactions only possible between processed dust and CIRRUS' clouds (after previous mixed-phase cloud occurrence). The details of dust IN activity in a given temperature and relative humidity environment depend on several factors, including dust particle mineralogy, size, chemical coatings, as well as the presence of other aerosols. Figure 8 presents a collection of recent laboratory data in the WARM_HET and COLD_HET cloud regions (introduced in Fig. 4) for uncoated and non-pre-activated mineral dust ice substrate samples of various sizes. Laboratory experiments show a fair amount of scatter, and it has been suggested that differences in dust particle size and composition, dust treatments (wet or dry dispersion into the experimental apparatus) and/or measurement techniques all play a role in this. Our modelling results indicate that the scatter in deposition IN laboratory results in region (iv), COLD_HET, is likely of little consequence in the atmosphere, at least to first order, because this 


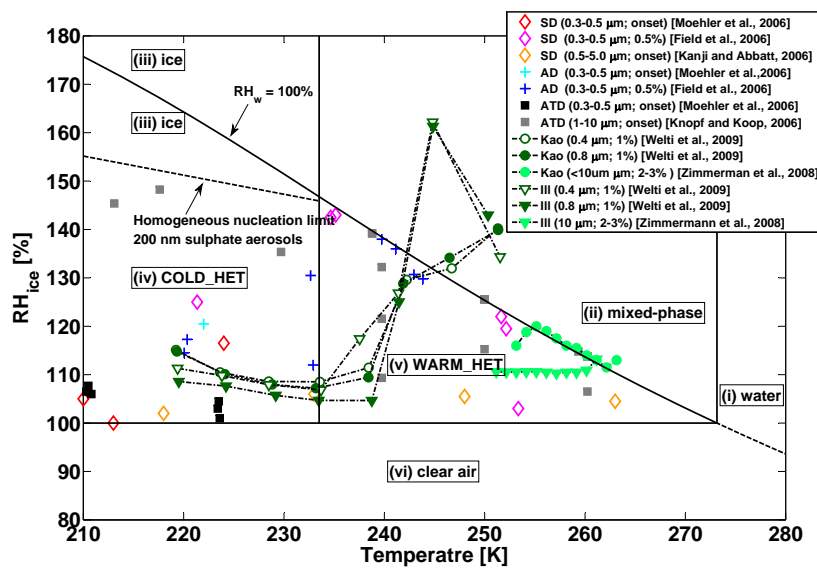

Fig. 8. Phase diagram as in Fig. 4, showing relative humidities measured in laboratory experiments addressing heterogeneous ice nucleation on naturally occurring, pure and refined mineral substrates $(\mathrm{SD}=$ Saharan Dust AD = Asian Dust ATD = Arizona Test Dust $;$ Kao $=$ Kaolinite; Ill = Illite) and using a number of techniques. The legend indicates the type and diameter of the particles studied (referring to a size distribution in the work of Möhler et al., 2006 and Field et al., 2006) and the criterion for the $\mathrm{RH}_{\mathrm{i}}$ recorded in or derived from the experiments (either for freezing onset or a minimum percentage of ice-activated particles, as indicated). Techniques represented include AIDA chamber (Möhler et al., 2006; Field et al., 2006), continuous flow diffusion chamber (Welti et al., 2009), and environmental scanning electron microscope (Zimmermann et al., 2008). Only single-nucleation-event data from Field et al. (2006) are shown.

is not a region that is sampled by our trajectories, i.e. there is no direct transport pathway for ice nuclei from deserts to the COLD_HET region. Stated differently, while these laboratory results are for uncoated (deposition) ice nuclei, any background IN in the COLD_HET region will have to have experienced deep convection and/or cloud processing, with the associated coating or pre-activation.

The situation is less understood in region (v), which represents WARM_HET clouds, and which is sampled by our trajectories throughout the year, i.e. there is a direct transport pathway for ice nuclei to these regions from desert sources. The scatter in laboratory data in region (v) shown in Fig. 8 does not allow us to answer the question of "How important are heterogeneously nucleated WARM_HET clouds?" with certainty. Moreover, at warmer temperatures laboratory data does not agree on whether ice is formed directly from the vapour (deposition nucleation) or through an intermediate liquid stage (immersion-freezing or condensation-freezing). In the follow-up laboratory study to Field et al. (2006), Connolly et al. (2009) describe only some deposition activity for $T<-16^{\circ} \mathrm{C}$ using $0.4 \mu \mathrm{m}$ Saharan dust particles, however, in their conclusions they indicate that warmer temperature deposition nucleation could have been underestimated in their study due to a lack of interstitial particles capable of acting as deposition IN. Using larger Saharan dust particles and longer experiments, Kanji and Abbatt (2006) report deposition nucleation at $263 \mathrm{~K}$. Lastly, using large and atmospherically abundant illite particles, but also using larger ice-activated fractions (2-3\%), Zimmermann et al. (2008) report ice nucleation at water subsaturated conditions for $T<260 \mathrm{~K}$.

Finally turning to field measurements, using a groundbased LIDAR system, Sassen (2005) reports the only measurements of desert dust serving as a deposition IN and creating ice clouds "at modest supersaturations and temperatures". The dust was Asian in origin in that study. Conversely, during a two month field campaign in southern Morocco (near the Saharan desert), Ansmann et al. (2008) observe that the presence of a high number of dust particles $\left(1-20 \mathrm{~cm}^{-3}\right)$ does not result in the production of ice particles at the top of the dust layer without temperature reaching about $-20^{\circ} \mathrm{C}$ and without the liquid condensed phase appearing first, although this may be due to the fact that less than one in 1000 dust particles will be active at $-20^{\circ} \mathrm{C}$. In a follow-up field campaign in Cape Verde (tropical Atlantic, downstream of Saharan dust sources), Ansmann et al. (2009) analyzed more than 200 different altocumulus layers, again finding that $99 \%$ of altocumulus layers showed a liquid cloud top (the region in which ice nucleation begins). However, limited conclusions can be made about which specific nucleation mechanisms were in operation given that the cloud observations were separated from the primary levels of Saharan dust.

In another ground-based LIDAR study in Japan, Sakai et al. (2004) describe measurements of ice production at the margins of a dry and depolarizing airmass that originated over the Gobi desert (Sakai et al., 2002); ice appears to have been first produced at $\sim 7.5 \mathrm{~km}$ altitude with $\mathrm{RH}_{\mathrm{i}}$ near or just over $100 \%$ and the temperature at the top of the ice cloud layer at $\sim-35^{\circ} \mathrm{C}$, which just falls into our WARM_HET cloud region (v), being too warm for the homogeneous freezing of pure water droplets and background sulphate solution droplets. The authors present evidence that moisture for the ice production was supplied by the intersection of the dry dust layer with a warm conveyor belt. While ice could have formed by deposition nucleation at the reported conditions, the authors note that measurement uncertainties cannot exclude other freezing modes.

\subsection{Geographic extent of most significant dust/cloud interactions}

We now present some details of the geographic extent and pressure of those trajectory points classified as MPC, WARM_HET, CIRRUS' and WATER. As discussed above, our transport trajectories are most likely to be dust-bearing during the peak of a given region's dust season; therefore, we show only the results from spring (MAM) for the Taklimakan, Gobi and Bodélé deserts, as well as from summer (JJA) for West African desert sources. (While the Bodélé is 
very active in winter, our trajectory analysis showed the least cloud formation during this time, hence we show the Bodélé in MAM for ease of comparison with the Asian deserts.)

The number of trajectory points classified as MPC clouds is shown in Fig. 9. There are approximately four times as many points fulfilling the MPC criteria in Asian regions as compared to African regions. Note that the color bars were allowed to saturate close to dust sources (shown in magenta) and also note that the scale changes between Asia and Africa in panels $a$ and b vs. $c$ and d. While Asian MPC clouds are found eastwards of the source deserts, African MPC clouds show the influence of both SW and NE transport patterns. Transport from the Taklimakan is more narrowly confined during March and April but extends to latitudes north of $45^{\circ} \mathrm{N}$ in May, while transport from the Gobi spans the full range of latitudes throughout MAM (monthly details not shown). In both Asian deserts, the pressure of MPC trajectory points decreases from March to May (not shown), but the pressure of Taklimakan MPC points is on average lower than the pressure of Gobi MPC points by approximately $100 \mathrm{hPa}$ (panels e and f). In Africa, transport from the Bodélé shows a NE peak in April and a SW peak in May, while transport from West Africa shows a similar strength of NE and SW transport in all summer months, increasing for both directions from June to August (monthly details not shown). The pressure of Bodélé MPC points is approximately $100 \mathrm{hPa}$ lower than the pressure of West African MPC points, likely due to a larger fraction of Bodélé MPC points being associated with deep convection in the intertropical convergence zone (ITCZ). Note that the pressure of Taklimakan MPC points, panel e is similar to that of Bodélé MPC points, panel h), but with a sharper peak at $400 \mathrm{hPa}$. Finally, we note again that the Taklimakan is a source of continuous, low-grade dust emissions (Wang et al., 2008) throughout much of the year, except winter (DJF). While not shown for brevity, JJA and SON Taklimakan MPC points show a similar geographic extent to MAM, with a minimum in transPacific transport in June and July, coinciding with the season of the slowest zonal flow. MPC points occur near western North America at lower pressures $(\sim 500 \mathrm{hPa})$ in September and October, and typically at $\sim 400 \mathrm{hPa}$ in spring and summer.

Figure 10 shows the geographic extent and pressure of trajectory points classified as WARM_HET clouds from all dust source regions. The patterns are similar to MPC clouds, with approximately four times more WARM_HET points originating from Asian than from African deserts, and with Taklimakan WARM_HET points occurring at lower pressures than Gobi WARM_HET points. As with MPC points, Taklimakan transport is more zonally confined than Gobi transport, except in May (not shown), which is consistent with the lower pressure (higher altitude) of Taklimakan transport, closer to the jet stream. However, WARM_HET points in general occur at slightly higher pressures (lower altitudes) than MPC points, where water saturation has not yet been reached. Finally, compared to MPC points in Fig. 9, there is less Asian WARM_HET points occurring in western North America, and there is less NE transport from West African dust sources.

The geographic extent of WATER clouds during the peak of the dust season (JJA) is shown for West Africa in Fig. 11. (Although Fig. 6 shows an overall peak in WATER clouds in the Bodéle in JJA, this is a time when dust emission is suppressed in this region, precisely because of the ongoing wet season.) Although mineral dust is a relatively poor cloud condensation nucleus, the large quantities emitted from West Africa and advected over the Atlantic (as shown) will certainly have some impact on warm clouds. Figure 11 also shows an influence extending to southern and western Europe (primarily in August, though this month is not shown by itself). In contrast, any effect of the Bodélé on WATER clouds (again not shown) is confined to sub-Saharan latitudes by the trade winds; this effect is expected during spring and fall, when the Bodélé source is active. WATER clouds were not shown in Asian regions due to the small magnitude of the effect and its occurrence outside of the peak dust emission season.

Lastly, Fig. 12 shows CIRRUS' clouds during the peak of the dust emission season (MAM) in the Taklimakan, which is the region of greatest CIRRUS' incidence (Fig. 6) The large potential geographic reach of CIRRUS' clouds originating from the Taklimakan is evident. We reiterate the uncertainties associated with this cloud type, which occurs subsequent to MPC formation after further lifting and cooling: as discussed previously, the fate of mineral dust in the preceding mixed-phase clouds is unclear and it is likely that a substantial fraction is lost due to in-cloud ice nucleation scavenging and below-cloud snow and rain scavenging. The spatial patterns are similar between the Taklimakan and the Gobi (not shown); moreover, the patterns are similar between MAM and JJA in the Taklimakan, when dust emission continues at a low level, as discussed above.

\subsection{Ascent characteristics by dust region}

The numerical nature of our study permits us to assess the characteristics of ascent of trajectories originating from each dust region. For Asian dust sources in particular, it is often stated in the literature that dust emitted from the Gobi desert travels at altitudes $<3 \mathrm{~km} 90 \%$ of the time, while dust emitted from the Taklimakan desert is easily entrained to altitudes $>5 \mathrm{~km}$ (e.g. Sun et al., 2001). African dust is always thought to travel at low altitudes in the Saharan Air Layer (Karyampudi et al., 1999). While the mixed boundary layer depth above the hotter African continent routinely reaches $5 \mathrm{~km}$, as stated earlier the melting level and the tropopause altitude above this low-latitude desert are correspondingly higher than in Asia.

We evaluated the percentage of trajectories from each dust emission region that ascended from the initial pressure of 

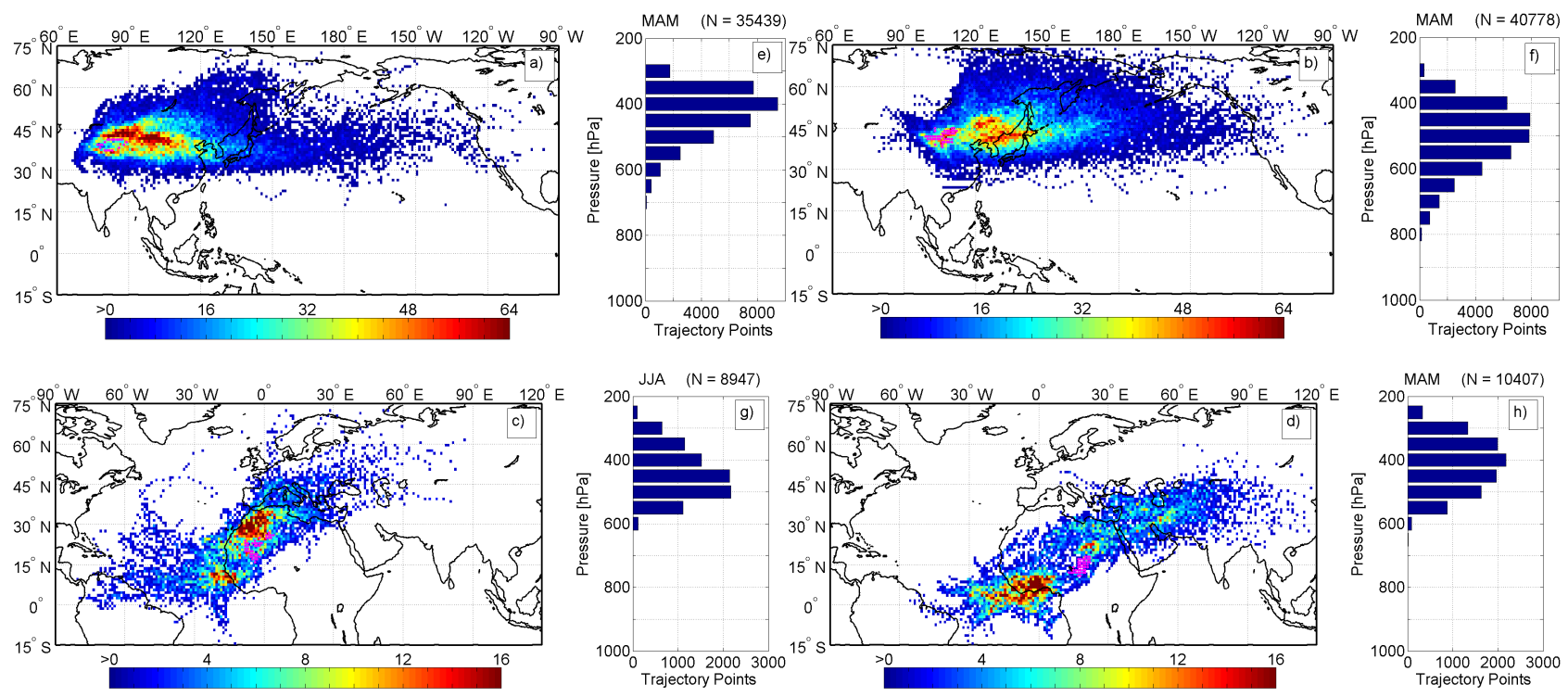

Fig. 9. Absolute number of trajectory points (in $1^{\circ} \times 1^{\circ}$ bins) classified as MPC clouds in trajectories originating from (a) Taklimakan, (b) Gobi, (c) West Africa and (d) Bodélé. Respective pressure [hPa] distributions are shown in panels (a-h). All panels show spring (MAM), except for (c) and (g), which show summer (JJA). Trajectory starting points are shown in magenta, with only perimeter points shown in the Taklimakan, for clarity.
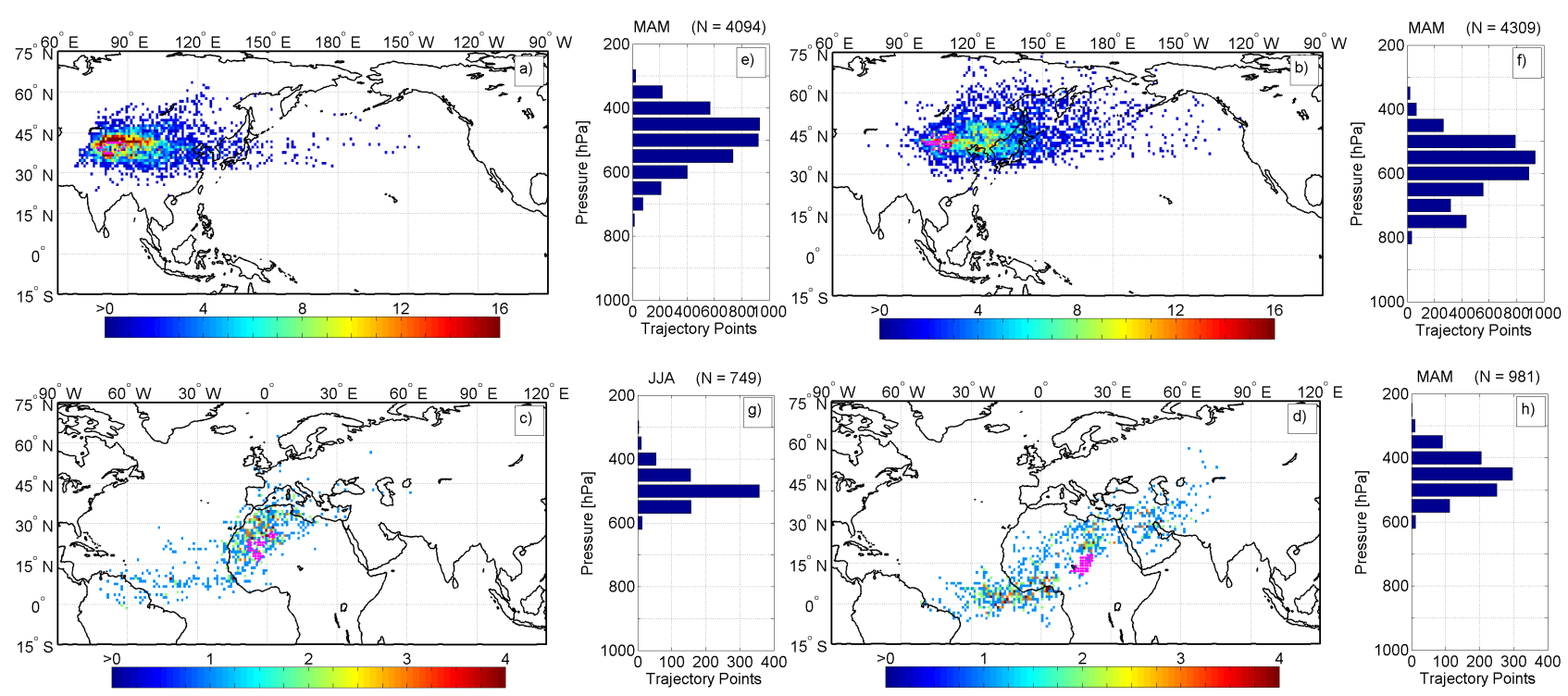

Fig. 10. Same as Fig. 9, except for WARM_HET trajectory points.

$770 \mathrm{hPa}$ to a number of different lower pressures (Fig. 13). We limited the investigation to March-April-May trajectories, except for West Africa, where we also evaluated the June-July-August period, which coincides with the peak of the dust emission season. We find that the Asian trajectories show a clear pattern of higher ascent than the African trajectories. This is consistent with the results of the case studies shown in Sect. 2.2. While Taklimakan trajectories always ascend to a higher altitude than Gobi trajectories, the latter ascend to jet stream levels $(\sim 300 \mathrm{hPa})$ in only approximately $10 \%$ of cases. This is true in both the eastern and western Gobi regions, as defined in Fig. 1, and it is consistent with the results of Sun et al. (2001) who also estimated that Mongolian and Chinese Gobi desert dust is entrained by the jet stream in $\sim 10 \%$ of dust emission cases. Our analysis indicates that Taklimakan trajectories ascend to $300 \mathrm{hPa} \sim 25 \%$ of the time in MAM (Fig. 13). Since the Taklimakan is dusty throughout the year, we examined ascent in other seasons 

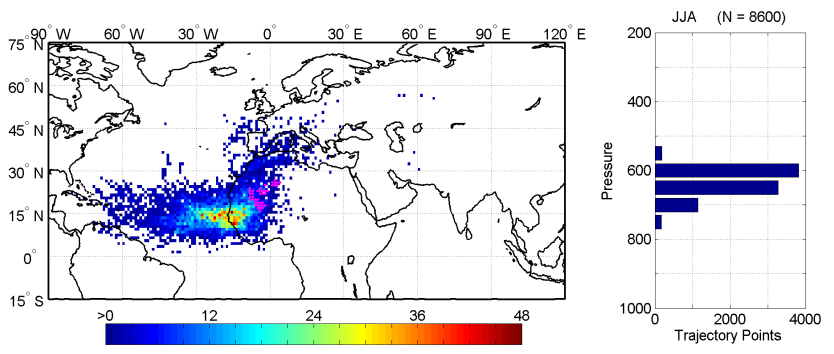

Fig. 11. WATER cloud points originating from West African dust sources (shown in magenta) in JJA.

(not shown) and found that nearly $40 \%$ of trajectories ascend to $300 \mathrm{hPa}$ in JJA, while only $\sim 10 \%$ ascend to the same pressure level in SON, with nearly no trajectories exhibiting ascent in DJF. Although we use extremely high resolution meteorological analyses, the ECMWF model still parameterizes turbulent processes as well as sub-grid scale convection, and our analysis may underestimate both the ascent of bare mineral dust by clear-air turbulent processes and the ascent of cloud-processed mineral dust via convective systems. A more detailed microphysical study is required to determine whether the under-estimate of convective dust ascent is balanced by the accompanying wet removal processes.

\section{Summary and outlook}

The availability of non-cloud processed mineral dust ice nuclei for interaction with warm and cold clouds was investigated using ECMWF meteorological analyses and $\sim 60000$ trajectory calculations originating from each of four major dust emitting regions in the world. We simulated transport trajectories for the duration of 2007, neglecting dust emission and deposition processes. Dust-bearing trajectories were assumed to be those coinciding with known dust emission seasons. The specific humidity at each trajectory's starting point was transported in a Lagrangian manner and relative humidities with respect to water and ice were calculated in 6-hr steps downstream, allowing us to estimate the formation of liquid, mixed-phase and ice clouds. The potential for uncoated mineral dust to affect cirrus clouds was found to be negligible, but a significant number of trajectories reached cirrus-forming regions after processing in mixed-phase clouds. This indicates that mineral dusts in cirrus forming regions are most relevant as immersion mode ice nuclei and perhaps also as deposition mode ice nuclei that have been pre-activated by one or more cycles of nucleation and evaporation within clouds, without having been scavenged to the surface.

By far the biggest potential impact of mineral dust was found to be on mixed-phase clouds themselves. However, the details of these interactions will depend on the efficiency of specific ice formation mechanisms in operation in

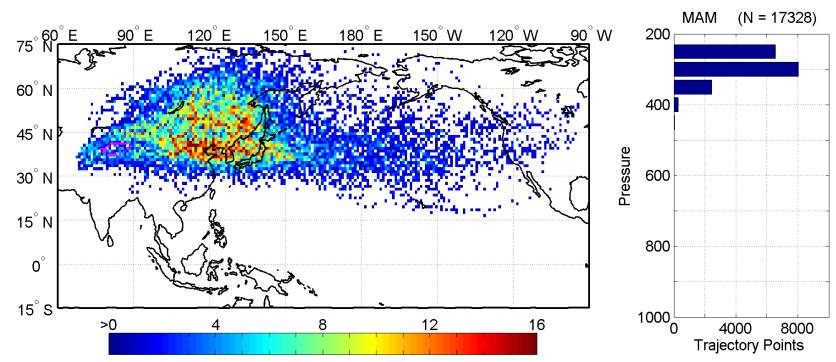

Fig. 12. CIRRUS' cloud points originating from Taklimakan desert (perimeter shown in magenta) in MAM.

a given relative humidity/temperature environment. This is also the case for a small but non-negligible number of trajectory points which passed through ice-saturated (but watersubsaturated) regions too warm for homogeneous nucleation, where "warm" cirrus clouds (WARM_HET) may be able to form by deposition freezing on dust IN. We reviewed some recent laboratory studies of ice nucleation at both cold and warm temperatures and we recommend that efforts continue to characterize both the ice formation mode (deposition nucleation, immersion-freezing, condensation-freezing, and contact nucleation) and ice production rates as a function of mineral particle size and composition, taking into account sample generation and dispersion methods (wet/dry), as well as the composition and thickness of atmospherically relevant coatings (e.g., water, sulphuric acid, nitric acid, ammonium sulphate, and dominant organic species). Given its potential role in efficient dehydration of the upper troposphere as well as in cloud seeding processes below, the variable IN efficiency of dust samples used in different laboratory experiments is important to reconcile, especially at warm temperatures. Finally, laboratory measurements of the effect of warm and mixed-phase cloud processing on bare mineral dust are necessary to reduce uncertainties in mineral dust concentrations and cloud lifetimes and distributions.

The geographic extent of our simulated mineral dust influence on warm and cold clouds was also presented for each region, focusing on mixed-phase and WARM_HET clouds, as defined in our study. Typical westerly transport patterns were reflected in our simulations of Asian dust/cloud interactions, extending to the western coast of North America; West African dust/cloud interactions affected the tropical Atlantic and North Africa as well as southern and western Europe; Bodélé dust/cloud interactions affected more southerly and easterly regions of the tropical Atlantic as well as the Middle East and south Asia. Additionally, trajectory ascent from each region was evaluated and it was found that both Asian regions (Taklimakan and Gobi) experienced significantly more ascent than African regions (West Africa and Bodélé). Taklimakan trajectories experienced the most ascent of all, with $\sim 25 \%, \sim 40 \%$ and $10 \%$ of trajectories reaching the $300 \mathrm{hPa}$ level in spring, summer and fall, respectively. 

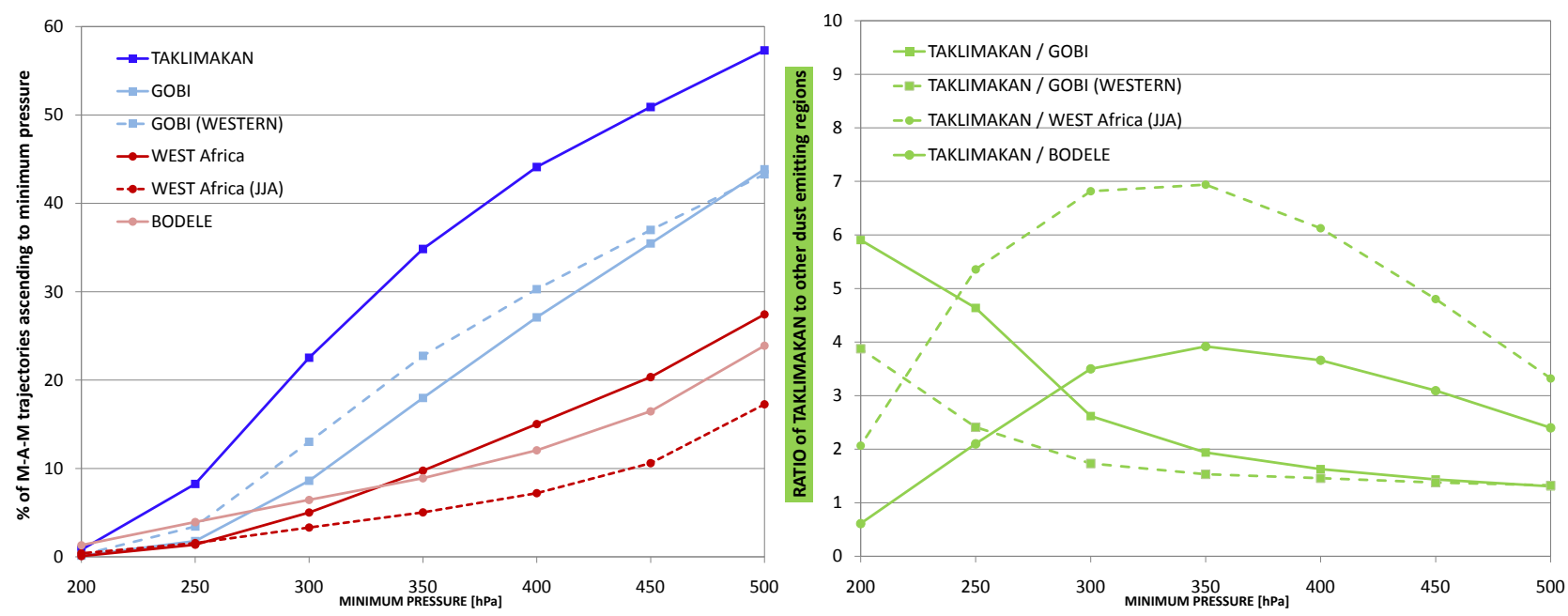

Fig. 13. Top panel shows percentage of March-April-May trajectories ascending to a given minimum pressure (hPa) from a starting pressure of $770 \mathrm{hPa}$ in the four geographic regions in our study, plus the western Gobi region, which is otherwise not shown in our results due to strong similarities with the eastern Gobi region. West Africa is also shown for June-July-August, when the peak of the dust emission season occurs. The bottom panel shows the ratio of ascending Taklimakan trajectories to those ascending in other dust emitting regions.

All effects on cold clouds were bigger from the Taklimakan and Gobi deserts in Asia than from both dust sources in Africa, despite the former being climatologically a much smaller dust emission source. As such, further field campaigns should include the Taklimakan desert and use instrumentation capable of resolving single particle microphysical processes (ice nucleation as well as warm and cold cloud processing) in real time and in situ, in addition to other complementary in situ, ground-based and remote sensing methods. The ability to resolve the ice formation mechanism is necessary in order to verify warm temperature deposition freezing processes, and hence the existence of WARM_HET clouds. While the Taklimakan is an interesting region to explore, the issue of the effects of dust on tropical convective transport and cyclone formation remains significant and complex (e.g., Evan et al., 2006).

When a wider range of data is available for the ice nucleation behaviour of atmospherically relevant mineral dust particles (bare and coated), the Lagrangian trajectory analysis described in this study can be extended to include microphysical processes involved in wet deposition by ice crystals and cloud droplets. Moreover, the approach can be used to study trajectories originating at various heights, especially in the deep Saharan atmospheric boundary layer. Thus expanded, the method would be ideally suited to simulate single case studies measured in the field and to test microphysical parameterizations for use in global climate models.

Acknowledgements. We thank D. Brunner for an introduction to LAGRANTO modelling, M. Sprenger for assistance with FORTRAN and Matlab programming, and S. Ferrachat for computational support. Helpful discussions are acknowledged in particular with D. Cziczo, and also with M. Baker, C. Hoose,
U. Krieger, C. Marcolli, P. Spichtinger, T. Storelvmo, M. Taddeo, I. Tegen, H. Wernli and B. Zobrist. Extensive use is made of meteorological analyses made available by the ECMWF in this work carried out primarily at ETH and supported by a Marie Curie Incoming International Fellowship awarded by the European Commission. Work at Dalhousie was supported by the Canadian Foundation for Climate and Atmospheric Science through the Cloud Aerosol Feedbacks on Climate network.

Edited by: Y. Balkanski

\section{References}

Andreae, M. O. and Rosenfeld, D.: Aerosol-cloud-precipitation interactions. Part 1. The nature and sources of cloud-active aerosols, Earth. Sci. Rev., 89, 13-41, 2008.

Ansmann, A., Mattis, I., Müller, D., Wandinger, U., Radlach, M., Althausen, D., and Damoah, R.: Ice formation in Saharan dust over central Europe observed with temperature/humidity/aerosol Raman lidar, J. Geophys. Res., 110, D18S12, doi:10.1029/2004JD005000, 2005.

Ansmann, A., Tesche, M., Althausen, D., et al.: Influence of Saharan dust on cloud glaciation in southern Morocco during the Saharan Mineral Dust Experiment, J. Geophys. Res., 113, D04210, doi:10.1029/2007JD008785, 2008.

Ansmann, A., Tesche, M., Seifert, P., Althausen, D., Engelmann, R., Fruntke, J., Wandinger, U., Mattis, I., and Muller D.: Evolution of the ice phase in tropical altocumulus: SAMUM lidar observations over Cape Verde, J. Geophys. Res., 114, D17208, doi:10.1029/2008JD011659, 2009.

Archuleta, C. M., DeMott, P. J., and Kreidenweis, S. M.: Ice nucleation by surrogates for atmospheric mineral dust and mineral dust/sulfate particles at cirrus temperatures, Atmos. Chem. Phys., 5, 2617-2634, doi:10.5194/acp-5-2617-2005, 2005. 
Bailey, M. and Hallett, J.: Nucleation effects on the habit of vapour grown ice crystals from -18 to $-42{ }^{\circ} \mathrm{C}$, Q. J. Roy. Meteorol. Soc., 128, 1461-1483, 2002.

Cakmur, R. V., Miller, R. L., Perlwitz, J., Geogdzhayev, I. V., Ginoux, P., Koch, D., Kohfeld, K. E., Tegen, I., and Zender, C. S.: Constraining the magnitude of the global dust cycle by minimizing the difference between a model and observations, J. Geophys. Res., 111, D06207, doi:10.1029/2005JD005791, 2006.

Connolly, P. J., Möhler, O., Field, P. R., Saathoff, H., Burgess, R., Choularton, T., and Gallagher, M.: Studies of heterogeneous freezing by three different desert dust samples, Atmos. Chem. Phys., 9, 2805-2824, doi:10.5194/acp-9-2805-2009, 2009.

Croft, B., Lohmann, U., Martin, R. V., Stier, P., Wurzler, S., Feichter, J., Hoose, C., Heikkilä, U., van Donkelaar, A., and Ferrachat, S.: Influences of in-cloud aerosol scavenging parameterizations on aerosol concentrations and wet deposition in ECHAM5-HAM, Atmos. Chem. Phys., 10, 1511-1543, doi:10.5194/acp-10-1511-2010, 2010.

Cziczo, D. J., Murphy, D. M., Hudson, P. K., and Thomson, D. S.: Single particle measurements of the chemical composition of cirrus ice residue during CRYSTAL-FACE, J. Geophys. Res., 109, D04201, doi:10.1029/2003JD004032, 2004a.

Cuesta, J., Marsham, J. H., Parker, D. J., and Flamant, C.: Dynamical mechanisms controlling the vertical redistribution of dust and the thermodynamic structure of the West Saharan atmospheric boundary layer during summer, Atmos. Sci. Lett., 10(1), 34-42, doi:10.1002/asl.207, 2009.

Cziczo, D. J., DeMott, P. J., Brooks, S. D., Prenni, A. J., Thomson, D. S., Baumgardner, D., Wilson, J. C., Kreidenweis, S. M., and Murphy, D. M.: Observations of organic species and atmospheric ice formation, Geophys. Res. Lett., 31, L12116, doi:10.1029/2004GL019822, 2004b.

DeMott, P. J., Cziczo, D. J., Prenni, A. J., Murphy, D. M., Kreidenweis, S. M., Thomson, D. S., Borys, R., and Rogers, D. C.: Measurements of the concentration and composition of nuclei for cirrus formation, P. Natl. Acad. Sci., 100, 14655-14660, doi:10.1073/pnas.2532677100, 2003a.

DeMott, P. J., Sassen, K., Poellot, M. R., Baumgardner, D., Rogers, D. C., Brooks, S. D., Prenni, A. J., and Kreidenweis, S. M.: African dust aerosols as atmospheric ice nuclei, Geophys. Res. Lett., 30(14), 1732, doi:10.1029/2003GL017410, 2003b.

Denman, K. L., Brasseur, G., Chidthaisong, A., Ciais, P., Cox, P. M., Dickinson, R. E., Hauglustaine, D., Heinze, C., Holland, E., Jacob, D., Lohmann, U., Ramachandran, S., da Silva Dias, P. L., Wofsy, S. C., and Zhang, X.: Couplings Between Changes in the Climate System and Biogeochemistry, in: Climate Change 2007: The Physical Science Basis. Contribution of Working Group I to the Fourth Assessment Report of the Intergovernmental Panel on Climate Change, edited by: Solomon, S., Qin, D., Manning, M., Chen, Z., Marquis, M., Averyt, K. B., Tignor, M., and Miller, H. L., Cambridge University Press, Cambridge, United Kingdom and New York, NY, USA, 2007.

Diehl, K., Simmel, M., and Wurzler, S.: Numerical sensitivity studies on the impact of aerosol properties and drop freezing modes on the glaciation, microphysics, and dynamics of clouds, J. Geophys. Res., 111, D07202, doi:10.1029/2005JD005884, 2006.

Eastwood, M. L., Cremel, S., Gehrke, C., Girard, E., and Bertram, A. K.: Ice nucleation on mineral dust particles: Onset conditions, nucleation rates and contact angles, J. Geophys. Res., 113,
D22203, doi:10.1029/2008JD010639, 2008.

Eastwood, M. L., Cremel, S., Wheeler, M., Murray, B. J., Girard, E., and Bertram, A. K.: Effects of sulfuric acid and ammonium sulfate coatings on the ice nucleation properties of kaolinite particles, Geophys. Res. Lett., 36, L02811, doi:10.1029/2008GL035997, 2009.

Engelstaedter, S., Tegen, I., and Washington, R.: North African dust emission and transport, Earth-Sci. Rev., 79, 73-100, 2006.

Evan, A. T., Dunion, J., Foley, J. A., Heidinger, A. K., and Velden, C. S.: New evidence for a relationship between Atlantic tropical cyclone activity and African dust outbreaks,, Geophys. Res. Lett., 33, L19813, doi:10.1029/2006GL026408, 2006.

Field, P. R., Möhler, O., Connolly, P., Krämer, M., Cotton, R., Heymsfield, A. J., Saathoff, H., and Schnaiter, M.: Some ice nucleation characteristics of Asian and Saharan desert dust, Atmos. Chem. Phys., 6, 2991-3006, doi:10.5194/acp-6-2991-2006, 2006.

Forster, P., Ramaswamy, V., Artaxo, P., Berntsen, T., Betts, R., Fahey, D. W., Haywood, J., Lean, J., Lowe, D. C., Myhre, G., Nganga, J., Prinn, R., Raga, G., Schulz, M., and Van Dorland, R.: Changes in Atmospheric Constituents and in Radiative Forcing, in: Climate Change 2007: The Physical Science Basis. Contribution of Working Group I to the Fourth Assessment Report of the IPCC, edited by: Solomon, S., Qin, D., Manning, M., Chen, Z., Marquis, M., Averyt, K. B., Tignor, M., and Miller, H. L., Cambridge University Press, Cambridge, United Kingdom and New York, NY, USA, 2007.

Herich, H., Tritscher, T., Wiacek, A., Gysel, M., Weingartner, E., Lohmann, U., Baltensperger, U., and Cziczo, D. J.: Water uptake of clay and desert dust aerosol particles at sub- and supersaturated water vapor conditions, Phys. Chem. Chem. Phys., 11, 7804-7809, doi:10.1039/b901585j, 2009.

Hobbs, P. V. and Rangno, A. L.: Ice particle concentrations in clouds, J. Atmos. Sci., 42, 2523-2549, 1985.

Hoffer, T. E.: A laboratory investigation of droplet freezing, J. Meteorol., 18, 766-778, 1961.

Holton, J. R., Haynes, P. H., McIntyre, M. E., Douglass, A. R., Rood, R. B., and Pfister, L.: Stratosphere-Troposphere Exchange, Rev. Geophys., 33(4), 403-439, 1995.

Hoose, C., Lohmann, U., Erdin, R., and Tegen, I.: The global influence of dust mineralogical composition on heterogeneous ice nucleation in mixed-phase clouds, Environ. Res. Lett., 3, 025003 , doi:10.1088/1748-9326/3/2/025003, 2008.

Isono, K, Komabayasi, M., and Ono, A.: The nature and the origin of ice nuclei in the atmosphere, J. Met. Soc. Jpn., 37(6), 211233, 1959.

Iwasaka, Y., Shi, G.-Y., Yamada, M., Matsuki, A., Trochkine, D., Kim, Y. S., Zhang, D., Nagatani, T., Shibata, T., Nagatani, M., Nakata, H., Shen, Z., Li, G., and Chen, B.: Importance of dust particles in the free troposphere over the Taklamakan Desert: Electron microscopic experiments of particles collected with a balloonborne particle impactor at Dunhuang, China, J. Geophys. Res., 108(D23), 8644, doi:10.1029/2002JD003270, 2003.

Kanji, Z. A. and Abbatt, J. P. D.: Laboratory studies of ice formation via deposition mode nucleation onto mineral dust and n-hexane soot samples, J. Geophys. Res., 111, D16204, doi:10.1029/2005JD006766, 2006.

Karyampudi, V. M., Palm, S. P., Reagen, J. A., Fang, H., Grant, W. B., Hoff, R. M., Moulin, C., Pierce, H. F., Torres, O., Browell, 
E. V., and Melfi, S. H.: Validation of the Saharan Dust Plume conceptual Model Using Lidar, Meteosat, and ECMWF Data, B. Am. Meteorol. Soc., 80, 1045-1075, 1999.

Knippertz, P., Ansmann, A., Althausen, D., Müller, D., Tesche, M., Bierwirth, E., Dinter, T., Müller, T., von Hoyningen-Huene, W., Schepanski, K., Wendisch, M., Heinold, B., Kandler, K., Petzold, A., Schütz, L., and Tegen, I.: Dust mobilization and transport in the northern Sahara during SAMUM 2006 - a meteorological overview, Tellus, 61B, 12-31, doi:10.1111/j.16000889.2008.00380.x, 2009.

Knopf, D. A. and Koop, T.: Heterogeneous nucleation of ice on surrogates of mineral dust, J. Geophys. Res., 111, D12201, doi:10.1029/2005JD006894, 2006.

Koch, J. and Renno, N. O.: The role of convective plumes and vortices on the global aerosol budget, Geophys. Res. Lett., 32, L18806, doi:10.1029/2005GL023420, 2005.

Koop, T., Luo, B., Tsias, A., and Peter, T.: Water activity as the determinant for homogeneous ice nucleation in aqueous solutions, Nature, 406, 611-614, 2000.

Kurosaki, Y. and Mikami, M.: Threshold wind speed for dust emission in east Asia and its seasonal variations, J. Geophys. Res., 112, D17202, doi:10.1029/2006JD007988, 2007.

Liu, D., Wang, Z., Liu, Z., Winker, D., and Trepte, C.: A height resolved global view of dust aerosols from the first year CALIPSO lidar measurements, J. Geophys. Res., 113, D16214, doi:10.1029/2007JD009776, 2008.

Mason, B. J. and Maybank, J.: Ice-nucleating properties of some natural mineral dusts, Q. J. Roy. Meteorol. Soc., 84, 235-241, 1958.

Matsuki, A., Iwasaka, Y., Osada, K., Matsunaga, K., Kido, M., Inomata, Y., Trochkine, D., Nishita, C., Nezuka, T., Sakai, T., Zhang, D., and Kwon, S.-A.: Seasonal dependence of the long-range transport and vertical distribution of free tropospheric aerosols over east Asia: On the basis of aircraft and lidar measurements and isentropic trajectory analysis, J. Geophys. Res., 108(D23), 8663, doi:10.1029/2002JD003266, 2003.

Miller, R. L., Cakmur, R. V., Perlwitz, J., Koch, D., Schmidt, G. A., Geogdzhayev, I. V., Ginoux, P., Prigent, C., and Tegen, I.: Mineral dust aerosols in the NASA Goddard Institute for Space Sciences ModelE atmospheric general circulation model, J. Geophys. Res., 111, D06208, doi:10.1029/2005JD005796, 2006.

Möhler, O., Field, P. R., Connolly, P., Benz, S., Saathoff, H., Schnaiter, M., Wagner, R., Cotton, R., Krämer, M., Mangold, A., and Heymsfield, A. J.: Efficiency of the deposition mode ice nucleation on mineral dust particles, Atmos. Chem. Phys., 6, 3007-3021, doi:10.5194/acp-6-3007-2006, 2006.

Möhler, O., Benz, S., Saathoff, H., Schnaiter, M., Wagner, R., Schneider, J., Walter, S., Ebert, V., and Wagner, S.: The effect of organic coating on the heterogeneous ice nucleation efficiency of mineral dust aerosols, Environ. Res. Lett., 3, 025007 , doi:10.1088/1748-9326/3/2/025007, 2008.

Pitter, R. L. and Pruppacher, H. R.: A wind tunnel investigation of freezing of small water drops falling at terminal velocity in air, Q. J. Roy. Meteorol. Soc., 99, 540-550, 1973.

Prospero, J. M., Ginoux, P., Torres, O., Nicholson, S. E., and Gill, T. E.: Environmental characterization of global sources of atmospheric soil dust identified with the Nimbus 7 Total Ozone Mapping Spectrometer (TOMS) absorbing aerosol product, Rev. Geophys., 40(1), 1002, doi:10.1029/2000RG000095, 2002.
Pruppacher, H. R. and Klett, J. D.: Microphysics of Clouds and Precipitation, 2nd ed., Kluwer Academic Publishers, Dordrecht, 976 pp., 1997.

Salam, A., Lohmann, U., Crenna, B., Lesins, G., Klages, P., Rogers, D., Irani, R., MacGillivray, A., and Coffin, M.: Ice Nucleation Studies of Mineral Dust Particles with a New Continuous Flow Diffusion Chamber, Aerosol Sci. Technol., 40, 134-143, 2006.

Sakai, T., Shibata, T., Iwasaka, Y., Nagai, T., Nakazato, M., Matsumura, T., Ichiki, A., Kim, Y.-S., Tamura, K., Troshkin, D., and Hamdi, S.: Case study of Raman lidar measurements of Asian dust events in 2000 and 2001 at Nagoya and Tsukuba, Japan, Atmos. Env., 36, 5479-5489, 2002.

Sakai, T., Nagai, T., Nakazato, M. and Matsumura, T.: Raman lidar measurement of water vapor and ice clouds associated with Asian dust layer over Tsukuba, Japan, Geophys. Res. Lett., 31, L06128, doi:10.1029/2003GL019332, 2004.

Sassen, K.: Indirect climate forcing over the western US from Asian dust storms, Geophys. Res. Lett., 29(10), 1465, doi:10.1029/2001GL014051, 2002.

Sassen, K., DeMott, P. J., Prospero, J. M., and Poellot, M. R.: Saharan dust storms and indirect aerosol effects on clouds: CRYSTAL-FACE results, Geophys. Res. Lett., 30(12), 1633, doi:10.1029/2003GL017371, 2003.

Sassen, K.: Dusty ice clouds over Alaska, Nature, 434, p. 456, 2005.

Satheesh, S. K. and Moorthy, K. K.: Radiative effects of natural aerosols: A review, Atmos. Environ., 39, 2089-2110, doi:10.1016/j.atmosenv.2004.12.029, 2005.

Schepanski, K., Tegen, I., Laurent, B., Heinold, B., and Macke, A.: A new Saharan dust source activation frequency map derived from MSG-SEVIRI IRchannels, Geophys. Res. Lett., 34, L18803, doi:10.1029/2007GL030168, 2007.

Seino, N., Sasaki, H., Yamamoto, A., Mikami, M., Zhou, H., and Zeng, F.: Numerical Simulation of Mesoscale Circulations in the Tarim Basin Associated with Dust Events, J. Met. Soc. Jpn., 83A, 205-218, 2005.

Shao, Y. and Wang, J.: A climatology of Northeast Asian dust events, Meteorol. Z., 12(4), 187-196, 2003.

Shao, Y. and Dong, C. H.: A review on East Asian dust storm climate, modelling and monitoring, Global Planet. Change, 52, 122, 2006.

Storelvmo, T., Kristjánsson, J. E., and Lohmann, U.: Aerosol Influence on Mixed-Phase Clouds in CAM-Oslo, J. Atmos. Sci., 65, 3214-3230, 2008.

Sun, J., Zhang, M., and Liu, T.: Spatial and temporal characteristics of dust storms in China and its surrounding regions, 19601999: Relations to source area and climate, J. Geophys. Res., 106(D10), 10325-10333, 2001.

Sun, Y., Tada, R., Chen, J., Liu, Q., Toyoda, S., Tani, A., Ji, J., and Isozaki, Y.: Tracing the provenance of fine-grained dust deposited on the central Chinese Loess Plateau, Geophys. Res. Lett., 35, L01804, doi:10.1029/2007GL031672, 2008.

Tanaka, T. Y. and Chiba, M.: A numerical study of the contributions of dust source regions to the global dust budget, Global Planet. Change, 52, 88-104, 2006.

Tegen, I.: Modeling the mineral dust aerosol cycle in the climate system, Quaternary Sci. Rev., 22, 1821-1834, doi:10.1016/S0277-3791(03)00163, 2003.

Textor, C., Schulz, M., Guibert, S., Kinne, S., Balkanski, Y., Bauer, 
S., Berntsen, T., Berglen, T., Boucher, O., Chin, M., Dentener, F., Diehl, T., Easter, R., Feichter, H., Fillmore, D., Ghan, S., Ginoux, P., Gong, S., Grini, A., Hendricks, J., Horowitz, L., Huang, P., Isaksen, I., Iversen, I., Kloster, S., Koch, D., Kirkevåg, A., Kristjansson, J. E., Krol, M., Lauer, A., Lamarque, J. F., Liu, X., Montanaro, V., Myhre, G., Penner, J., Pitari, G., Reddy, S., Seland, Ø., Stier, P., Takemura, T., and Tie, X.: Analysis and quantification of the diversities of aerosol life cycles within AeroCom, Atmos. Chem. Phys., 6, 1777-1813, doi:10.5194/acp-61777-2006, 2006.

Tompkins, A. M., Gierens, K., and Rädel, G.: Ice supersaturation in the ECMWF integrated forecast system, Q. J. Roy. Meteorol. Soc., 133, 53-67, doi:10.1002/qj.14, 2007.

Tsai, F., Chen, G. T.-J., Liu, T.-H., Lin, W.-D., and Tu, J.-Y.: Characterizing the transport pathways of Asian dust, J. Geophys. Res., 113, D17311, doi:10.1029/2007JD009674, 2008.

Twohy, C. H. and Poellot, M. R.: Chemical characteristics of ice residual nuclei in anvil cirrus clouds: evidence for homogeneous and heterogeneous ice formation, Atmos. Chem. Phys., 5, 22892297, doi:10.5194/acp-5-2289-2005, 2005.

Uno, I., Harada, K., Satake, S., Hara, Y., and Wang, Z.: Meteorological Characteristics and Dust Distribution of the Tarim Basin Simulated by the Nesting RAMS/CFORS Dust Model, J. Met. Soc. Jpn., 83A, 219-239, 2005.

Untch, A., Miller, M., Hortal, M., Buizza, R., and Janssen, P.: Towards a global meso-scale model: The high-resolution system T799L91 and T399L62 EPS, ECMWF Newsletter, No. 108, Summer, 2006.

Wang, X., Huang, J., Ji, M., and Higuchi, K.: Variability of East Asia dust events and their long-term trend, Atmos. Environ., 42, 3156-3165, 2008.
Washington, R. and Todd, M. C.: Atmospheric controls on mineral dust emission from the Bodélé Depression, Chad: The role of the low level jet, Geophys. Res. Lett., 32, L17701, doi:10.1029/2005GL023597, 2005.

Welti, A., Lüönd, F., Stetzer, O., and Lohmann, U.: Influence of particle size on the ice nucleating ability of mineral dusts, Atmos. Chem. Phys., 9, 6705-6715, doi:10.5194/acp-9-6705-2009, 2009.

Wernli, H. and Davies, H. C.: A Lagrangian-based analysis of extratropical cyclones. I: The method and some applications, Q. J. Roy. Meteorol. Soc., 123, 467-489, 1997.

Wiacek, A. and Peter, T.: On the availability of uncoated mineral dust ice nuclei in cold cloud regions, Gephys. Res. Lett., 36, L17801, doi:10.1029/2009GL039429, 2009.

Wiacek, A., Peter, T., and Taddeo, M.: Mineral dust: observations of emission events and modeling of transport to the upper troposphere, IGAC Newsletter, vol. 40, available at: http://www.igac. noaa.gov/newsletter/igac40/Jan_2009_IGAC_40.pdf, 2009.

Winker, D. M., Hunt, W. H., and McGill, M. J.: Initial performance assessment of CALIOP, Geophys. Res. Lett., 34, L19803, doi:10.1029/2007GL030135, 2007.

Zender, C. S., Bian, H., and Newman, D.: Mineral Dust Entrainment and Deposition (DEAD) model: Description and 1990s dust climatology, J. Geophys. Res., 108(D14), 4416, doi:10.1029/2002JD002775, 2003.

Zimmermann, F., Weinbruch, S., Schütz, L., Hofmann, H., Ebert, M., Kandler, K., and Worringen, A.: Ice nucleation properties of the most abundant mineral dust phases, J. Geophys. Res., 113, D23204, doi:10.1029/2008JD010655, 2008. 